\title{
Reanalysis of a 10-year record (2004-2013) of seasonal mass balances at Langenferner/Vedretta Lunga, Ortler Alps, Italy
}

\author{
Stephan Peter Galos ${ }^{1}$, Christoph Klug ${ }^{2}$, Fabien Maussion ${ }^{1}$, Federico Covi ${ }^{1,3}$, Lindsey Nicholson ${ }^{1}$, Lorenzo Rieg ${ }^{2}$, \\ Wolfgang Gurgiser ${ }^{1}$, Thomas Mölg ${ }^{4}$, and Georg Kaser ${ }^{1}$ \\ ${ }^{1}$ Institute of Atmospheric and Cryospheric Sciences, University of Innsbruck, Innsbruck, Austria \\ ${ }^{2}$ Institute of Geography, University of Innsbruck, Innsbruck, Austria \\ ${ }^{3}$ Geophysical Institute, University of Alaska, Fairbanks, USA \\ ${ }^{4}$ Climate System Research Group, Institute of Geography, Friedrich Alexander University Erlangen-Nürnberg (FAU), \\ Erlangen-Nürnberg, Germany
}

Correspondence to: Stephan Peter Galos (stephan.galos@uibk.ac.at)

Received: 15 December 2016 - Discussion started: 10 January 2017

Revised: 16 May 2017 - Accepted: 18 May 2017 - Published: 22 June 2017

\begin{abstract}
Records of glacier mass balance represent important data in climate science and their uncertainties affect calculations of sea level rise and other societally relevant environmental projections. In order to reduce and quantify uncertainties in mass balance series obtained by direct glaciological measurements, we present a detailed reanalysis workflow which was applied to the 10-year record (2004 to 2013) of seasonal mass balance of Langenferner, a small glacier in the European Eastern Alps. The approach involves a methodological homogenization of available point values and the creation of pseudo-observations of point mass balance for years and locations without measurements by the application of a process-based model constrained by snow line observations. We examine the uncertainties related to the extrapolation of point data using a variety of methods and consequently present a more rigorous uncertainty assessment than is usually reported in the literature.

Results reveal that the reanalyzed balance record considerably differs from the original one mainly for the first half of the observation period. For annual balances these misfits reach the order of $>300 \mathrm{~kg} \mathrm{~m}^{-2}$ and could primarily be attributed to a lack of measurements in the upper glacier part and to the use of outdated glacier outlines. For winter balances respective differences are smaller (up to $233 \mathrm{~kg} \mathrm{~m}^{-2}$ ) and they originate primarily from methodological inhomogeneities in the original series. Remaining random uncertainties in the reanalyzed series are mainly determined by the extrapolation of point data to the glacier scale and are
\end{abstract}

on the order of $\pm 79 \mathrm{~kg} \mathrm{~m}^{-2}$ for annual and $\pm 52 \mathrm{~kg} \mathrm{~m}^{-2}$ for winter balances with values for single years/seasons reaching $\pm 136 \mathrm{~kg} \mathrm{~m}^{-2}$. A comparison of the glaciological results to those obtained by the geodetic method for the period 2005 to 2013 based on airborne laser-scanning data reveals that no significant bias of the reanalyzed record is detectable.

\section{Introduction}

Long-term records of glacier mass balance are of particular interest to the scientific community as they reflect the most direct link between observed glacier changes and the underlying atmospheric drivers (e.g., Hoinkes et al., 1967; Dyurgerov and Meier, 2000; Kaser et al., 2006; Mölg et al., 2009a). During the past decades, considerable effort has been made to establish programs which provide mass balance information of individual glaciers from all over the world (e.g., Zemp et al., 2009; WGMS, 2015). These records are undoubtedly valuable and, among others, form the basis for the assessment of glacier contribution to current sea level rise (Church et al., 2013). However, their usefulness is bounded by inhomogeneities and unquantified uncertainties in the limited number of available records (e.g., Cogley, 2009; Gardner et al., 2013; Zemp et al., 2009, 2015).

Recently, a number of studies have addressed the topic of inhomogeneous, biased and erroneous glacier mass balance 
records (e.g., Rolstad et al., 2009; Koblet et al., 2010; Zemp et al., 2010; Andreassen et al., 2012). The number of point measurements needed to derive glacier-wide mass balance was discussed by Fountain and Vecchia (1999) and Pelto (2000), while Jansson (1999) investigated the uncertainties related to direct measurement techniques and the appropriate number of measurement points at Storglaciären. Several studies have attempted to quantify how different methods of extrapolating point measurements to the glacier scale affect the resultant glacier mass balance (e.g., Funk et al., 1997; Hock and Jensen, 1999; Sold et al., 2016). Others focused on statistical approaches to evaluate annual or seasonal glacier mass balance and their associated confidence level (e.g., Lliboutry, 1974; Thibert and Vincent, 2009; Eckert et al., 2011). But despite the relatively high number of studies dedicated to the reanalysis of glacier mass balance records, few of them (e.g., Thibert et al., 2008; Eckert et al., 2011) include a rigorous uncertainty analysis. Consequently, error assessment and reanalysis of glaciological data is of central interest to both the glaciological and climatological community (Zemp et al., 2013, 2015).

Zemp et al. (2013) provided a general concept for reanalyzing glacier mass balance series and the quantification of related uncertainties in the context of comparisons between directly measured and geodetically derived mass balance which are commonly undertaken to cross-check the in situ glaciological data (e.g., Funk et al., 1997; Øtrem and Haakensen, 1999; Cox and March, 2004; Thibert et al., 2008; Cogley, 2009).

Since many records of glacier mass balance suffer from data gaps affecting certain time periods or areas without measurements, a series of methods has been developed to complete the respective data sets. Such reconstructions are often based on the assumption that glacier mass balance gradients are transferable in space or time (e.g., Haefeli, 1962; Rasmussen, 2004; Kuhn et al., 2009) or on other statistical relationships of varying complexity (e.g., Lliboutry, 1974; Carturan et al., 2009; Thibert and Vincent, 2009). However, all those methods rely on statistical relationships which are assumed to be stationary in time or space. This in turn limits the performance of such approaches as they are not able to depict the full natural variability of glacier mass balance.

As a consequence, the use of subsidiary tools such as distributed surface mass balance models, extensive accumulation measurements and auxiliary imagery have become more commonly used components of mass balance (re-)analyses. Mass balance models have been used to extrapolate point measurements to the glacier scale (e.g., Huss et al., 2009, 2013; Sold et al., 2016), to homogenize annual or seasonal mass balance with respect to the fixed date method (Huss et al., 2009) or to investigate the impact of changing glacier area and hypsometry on values of mean specific mass balance (Paul, 2010; Huss et al., 2012). Extensive accumulation measurements (e.g., Sold et al., 2016) provide detailed information on the intractable problem of spatial variability of snow accumulation while additional optical imagery gives information on the evolving snow cover (e.g., Huss et al., 2013; Barandun et al., 2015; Kronenberg et al., 2016).

In this paper we present a reanalysis of the mass balance record of a small alpine glacier over the 10-year period of 2004 to 2013 including a thorough uncertainty assessment. The example glacier is a particularly useful case as, like for many other glacier mass balance records, the measurement network has changed over time and the data record suffers from inconsistencies that must be tackled in order to create a consistent homogenized time series. Thus, developing a reanalyzed record and providing a detailed analysis of the uncertainty associated with this record showcases a method that can be applied to glacier data sets suffering from similar inconsistencies. Furthermore it provides insights into the reliability of existing glacier mass balance series for which such error analyses are not possible or practical. The reanalysis presented here involves the following:

i. The creation of a complete and consistent set of point mass balance by correcting for methodological shortcomings in the original data and the creation of pseudopoint measurements for years and locations without measurements applying a physical mass balance model ensuring maximum skill by integrating available snow line observations into the reanalyzed record.

ii. The recalculation of glacier-wide mass balance based on a variety of extrapolation techniques and the integration of new topographic data from orthoimages and airborne laser scanning (ALS) in order to minimize the effect of changing glacier outlines on the glacier-wide mass balance.

iii. A sound uncertainty assessment regarding the results of this study including a comparison of the reanalyzed cumulative mass balance to the mass change obtained from the geodetic method based on airborne laserscanning data.

\section{Study site and data}

\subsection{Langenferner}

Langenferner (Vedretta Lunga) is a small valley glacier situated at the head of the Martell Valley $\left(46.46^{\circ} \mathrm{N}, 10.61^{\circ} \mathrm{E}\right)$ in the Ortler-Cevedale Group, Autonomous Province of Bozen, Italy (Fig. 1). It covers an area of $1.6 \mathrm{~km}^{2}$ (2013) and the highest point of the glacier is an ice divide at around 3370 ma.s.l. The terminus elevation is 2711 ma.s.l. and the median altitude is 3143 ma.s.l. (Galos et al., 2015). The upper glacier part is mainly exposed to the north while the lower sections face east. Only a minor fraction $(<3 \%)$ of the glacier surface is debris covered. Ground-penetrating radar 


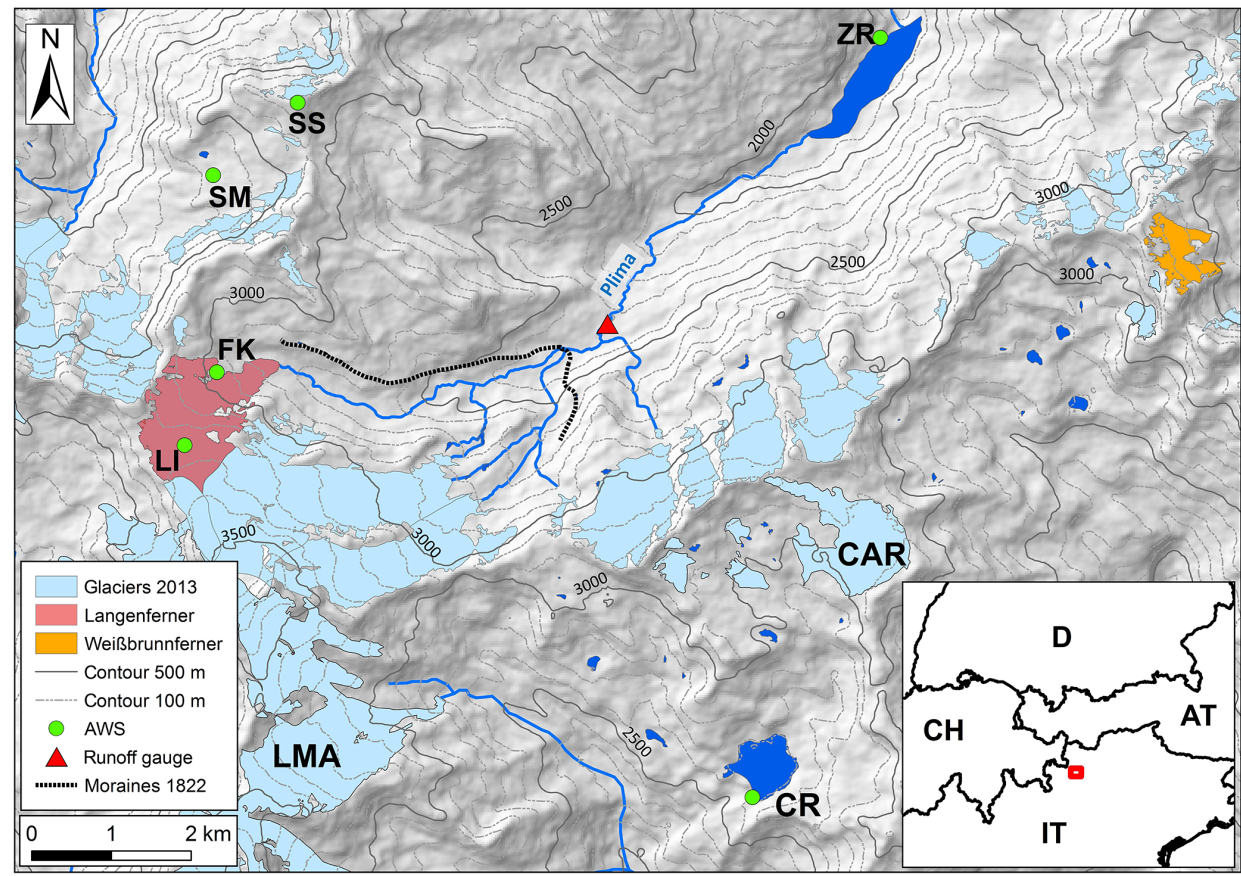

Figure 1. Overview of the study area. Langenferner is shown in red, Weißbrunnferner in orange and other glaciers in light blue (glacier outlines of 2013 derived from ALS; Galos et al., 2015). Green dots indicate the automated weather stations referred to in this study: Zufritt reservoir (ZR), Schöntaufspitze (SS), Sulden Madritsch (SM), Felsköpfl (FK), Langenferner Ice (LI) and Careser Dam Station (CR). The labels LMA and CAR refer to two other glaciers with mass balance measurements: La Mare and Careser (e.g., Carturan et al., 2012).

measurements in spring 2010 gave a glacier volume of approximately $0.08 \mathrm{~km}^{3}$, with a maximum thickness of more than $100 \mathrm{~m}$ in the upper glacier part. The glacier runoff feeds the river Plima, which is a tributary to the river Etsch (Adige).

Langenferner is situated at the southern periphery of the inner alpine dry zone, and thus the climate is shaped by relatively dry conditions due to precipitation shadow effects from surrounding mountain ranges. The largest part of annual precipitation is associated with air flow from southern directions, often resulting from cyclonic activity over the Mediterranean, while the location south of the main Alpine divide means that fronts from the north are of only minor importance. Mean annual precipitation rates in the region range from about $500 \mathrm{~kg} \mathrm{~m}^{-2}$ at the bottom of the Vinschgau (Valle Venosta) to about $800 \mathrm{~kg} \mathrm{~m}^{-2}$ at Zufritt reservoir (1851 ma.s.1.), up to approximately $1200 \mathrm{~kg} \mathrm{~m}^{-2}$ at Careser Reservoir Station, 2605 ma.s.l. (Carturan et al., 2012). During the study period the mean zero degree level as inferred from the automatic weather stations (AWS) used in this study was at an altitude of $2500 \mathrm{~m}$ a.s.l. As in most regions of the Eastern Alps, glaciers in the Ortler Alps have been far from equilibrium during the past decade and have hence experienced drastic loss in mass, area and volume (e.g., Carturan et al., 2013; D'Agata et al., 2014). A comparison of the geodetic mass balance of Langenferner $\left(-9.4 \times 10^{3} \mathrm{~kg} \mathrm{~m}^{-2}\right)$ to those of about 90 other glaciers in the Etsch catchment (sample mean: $-6.0 \times 10^{3} \mathrm{~kg} \mathrm{~m}^{-2}$ ) shows that at least dur- ing the period 2005 to 2013 Langenferner was amongst the glaciers with the most negative glacier-wide specific mass balances in the region (Galos et al., 2015).

\subsection{Glaciological measurements}

Direct glaciological measurements at Langenferner were initiated by the University of Innsbruck on behalf of the Hydrological Office of the Autonomous Province of Bozen/Südtirol (HOB) in the hydrological year 2004. The program was established as a supplement to the mass balance program at Weißbrunnferner/Fontana Bianca, which was (i) considered as potentially threatened by rapid glacier retreat and (ii) deemed to be not representative for the region due to the specific setting of the glacier (Kaser et al., 1995). Since the start of the program, the initially provisional measurement network has gradually evolved (Fig. 2) and, hence, has changed substantially over time, especially in terms of spatial stake distribution, which poses a particular challenge for understanding the spatiotemporal variability of the glacier mass balance.

In autumn 2002, a number of ablation stakes were installed in the lower part of Langenferner and systematic readings began in October 2003, when additional stakes were drilled, still only covering the lover half of the glacier. In August 2005, the stake network was extended to the upper glacier sections by adding seven more stakes, the position of 

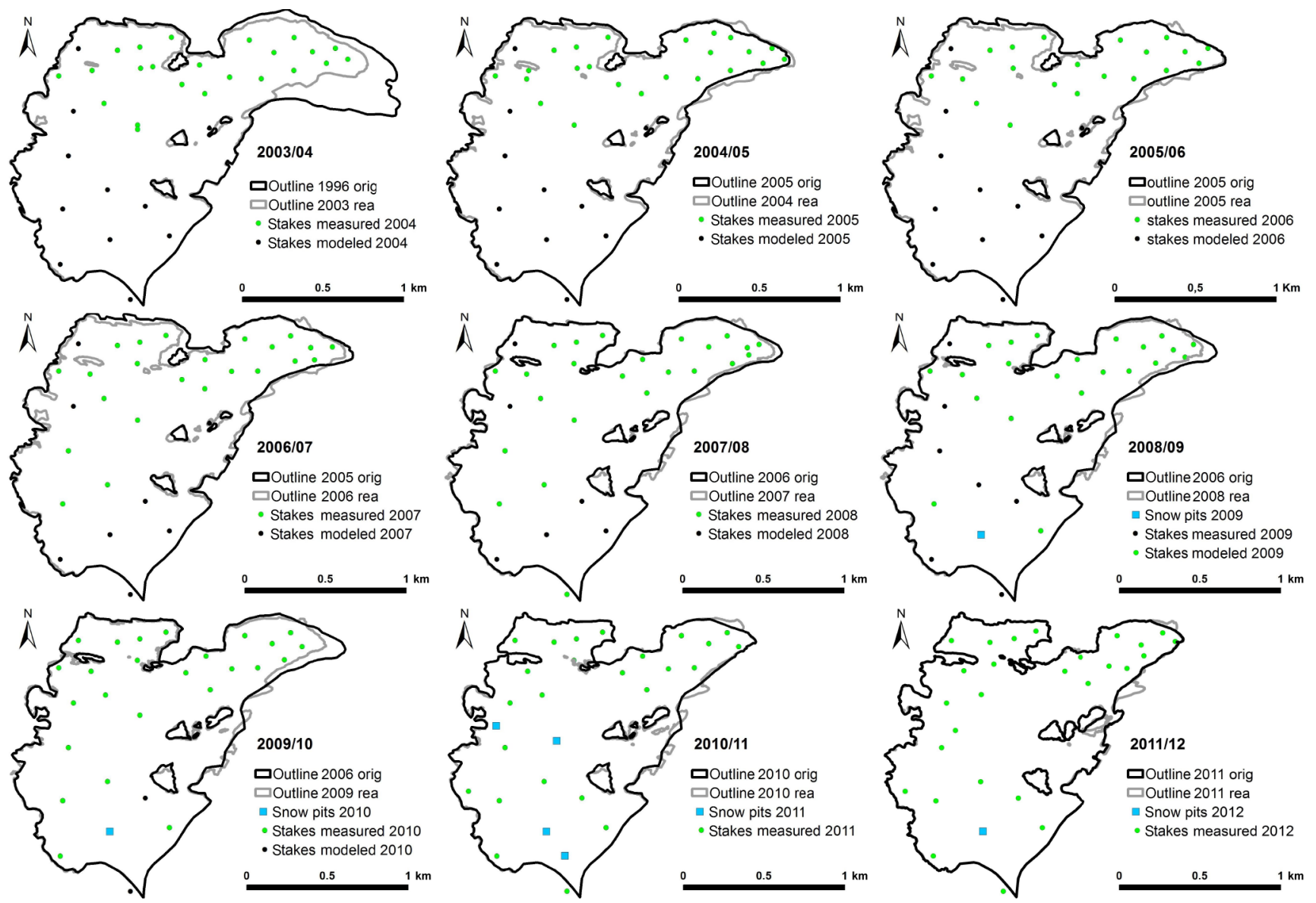

Figure 2. Measured and modeled point balances as used for the calculation of annual balance at Langenferner. Black glacier outlines are those used in the original analyses while gray lines refer to the reanalyzed outlines used in this study. Green and blue symbols indicate direct measurements which were used in the original analyses and after homogenization also in this study. Black dots symbolize modeled point values generated and used in the reanalysis.

which was initially not accurately recorded. Systematic readings of the stakes in the upper glacier part at the end of the hydrological year were not performed regularly until the year 2009 , when the measurement network was further refined by adding five additional stakes to the upper glacier sections. In the course of the study period four stakes in the lower most glacier part were removed after the respective locations became free of ice. The position of stake 13 in the middle part of the glacier had to be changed in 2011 due to outcropping rock at the original location.

The stake network at the end of the study period (2013) was made up of 30 ablation stakes which consist of elastic white PVC tubes of roughly $2 \mathrm{~m}$ length, connected by a piece of rubber hose. Drilling depths vary between $4 \mathrm{~m}$ in the uppermost glacier part and $12 \mathrm{~m}$ in the lower sections. During the study period stake readings were performed once to six times a year, depending on the local conditions at the individual stake. Extensive measurements of annual net accumulation at the end of summer were only necessary in the years 2010 and 2013 when the accumulation area ratio
(AAR) made up for about 37 and $50 \%$ of the total glacier area, respectively. In the other observation years accumulation areas were restricted to only a few percent of the total glacier area (see Table 1). Up to the year 2007 no measurements of annual net accumulation were performed. From 2008 to 2013, annual net accumulation was measured at the end of the hydrological year by means of one to four snow pits at more or less arbitrarily chosen locations and, if necessary, by a varying number of snow depth probings.

Winter balance measurements have been carried out annually in the first half of May performing numerous snow depth probings and four (or three) snow pits distributed over the glacier surface in each of which the bulk density of the snow pack was measured gravimetrically. While the number and location of the snow depth probings were not fixed throughout the observation period, the number and positions of the pits were more or less kept constant, except for the year 2009 when the large amount of winter accumulation resulted in omitting pit 3. Locations of point measurements used for annual mass balance are shown in Fig. 2, measurement loca- 
Table 1. Reanalyzed and original annual and seasonal mass balances and corresponding glaciological key numbers for Langenferner. $S_{\text {rea }}$ stands for the glacier area used in the reanalysis, $N_{\text {tot }}$ is the total number of point mass balances used for glacier-wide reanalysis calculations, $N_{\text {mod }}$ is the number of modeled point balances, $B_{\text {ref }}$ is the resulting glacier-wide specific balance, $\sigma_{\text {glac.tot }}$ is the total random error and

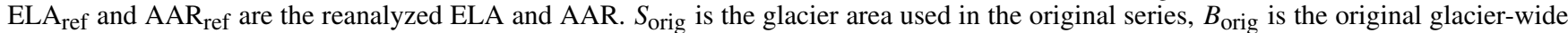
specific balance, ELA orig $_{\text {and }} \mathrm{AAR}_{\text {orig }}$ are the original ELA and AAR and orig-ref refers to the difference between original and reanalyzed record. Bold entries refer to results which are influenced by mass balance modeling.

\begin{tabular}{|c|c|c|c|c|c|c|c|c|c|c|c|c|}
\hline \multicolumn{13}{|c|}{ Annual } \\
\hline Year & $S_{\text {rea }}$ & $N_{\text {tot }}$ & $N_{\text {mod }}$ & $B_{\text {ref }}$ & $\sigma_{\text {glac.tot }}$ & ELA $_{\text {ref }}$ & $\mathrm{AAR}_{\text {ref }}$ & $S_{\text {orig }}$ & $B_{\text {orig }}$ & ELA $_{\text {orig }}$ & $\mathrm{AAR}_{\text {orig }}$ & orig-ref \\
\hline & $\mathrm{km}^{2}$ & & & $\mathrm{~kg} \mathrm{~m}^{-2}$ & $\mathrm{~kg} \mathrm{~m}^{-2}$ & ma.s.1. & $\%$ & $\mathrm{~km}^{2}$ & $\mathrm{~kg} \mathrm{~m}^{-2}$ & ma.s.1. & $\%$ & $\mathrm{~kg} \mathrm{~m}^{-2}$ \\
\hline 2004 & 1.938 & 32 & 10 & -1140 & 41 & $>h_{\max }$ & 12 & 2.030 & -1524 & $>h_{\max }$ & 0 & -384 \\
\hline 2005 & 1.864 & 33 & 10 & -1456 & 59 & $>h_{\max }$ & 5 & 1.858 & -1233 & $>h_{\max }$ & 0 & 223 \\
\hline 2006 & 1.833 & 30 & 10 & -1514 & 38 & $>h_{\max }$ & 4 & 1.858 & -1456 & 3320 & 10 & 58 \\
\hline 2007 & 1.821 & 30 & 7 & -1539 & 127 & $>h_{\max }$ & 5 & 1.858 & -1616 & $>h_{\max }$ & 0 & -77 \\
\hline 2008 & 1.785 & 32 & 6 & -1318 & 136 & $>h_{\max }$ & 11 & 1.776 & -1637 & 3320 & 8 & -319 \\
\hline 2009 & 1.754 & 30 & 7 & -942 & 62 & 3278 & 18 & 1.776 & -998 & 3285 & 16 & -56 \\
\hline 2010 & 1.722 & 28 & 2 & -493 & 82 & 3249 & 37 & 1.776 & -659 & 3267 & 23 & -166 \\
\hline 2011 & 1.693 & 29 & 0 & -1166 & 91 & $>h_{\max }$ & 7 & 1.692 & -1078 & $>h_{\max }$ & 10 & 88 \\
\hline 2012 & 1.659 & 28 & 0 & -1556 & 47 & $>h_{\max }$ & 1 & 1.656 & -1532 & $>h_{\max }$ & 1 & 24 \\
\hline 2013 & 1.620 & 100 & 0 & -246 & 31 & 3088 & 50 & 1.656 & -221 & 3085 & 53 & 25 \\
\hline \multicolumn{13}{|c|}{ Winter } \\
\hline 2004 & 1.938 & 22 & 0 & 1022 & 96 & $<h_{\min }$ & 100 & 2.030 & 1083 & $<h_{\min }$ & 100 & 61 \\
\hline 2005 & 1.864 & 87 & 0 & 750 & 50 & $<h_{\min }$ & 100 & 1.858 & 772 & $<h_{\min }$ & 100 & 22 \\
\hline 2006 & 1.833 & 47 & 0 & 925 & 40 & $<h_{\min }$ & 100 & 1.858 & 1039 & $<h_{\min }$ & 100 & 114 \\
\hline 2007 & 1.821 & 48 & 0 & 558 & 44 & 2736 & 97 & 1.858 & 642 & $<h_{\min }$ & 100 & 84 \\
\hline 2008 & 1.785 & 36 & 0 & 814 & 47 & $<h_{\min }$ & 100 & 1.776 & 849 & $<h_{\min }$ & 100 & 35 \\
\hline 2009 & 1.754 & 61 & 0 & 1267 & 34 & $<h_{\min }$ & 100 & 1.776 & 1343 & $<h_{\min }$ & 100 & 76 \\
\hline 2010 & 1.722 & 80 & 0 & 837 & 56 & $<h_{\min }$ & 100 & 1.776 & 1076 & $<h_{\min }$ & 100 & 233 \\
\hline 2011 & 1.693 & 127 & 0 & 965 & 34 & $<h_{\min }$ & 100 & 1.692 & 944 & $<h_{\min }$ & 100 & -21 \\
\hline 2012 & 1.659 & 58 & 0 & 942 & 53 & $<h_{\min }$ & 100 & 1.656 & 995 & $<h_{\min }$ & 100 & 63 \\
\hline 2013 & 1.620 & 109 & 0 & 1213 & 32 & $<h_{\min }$ & 100 & 1.656 & 1255 & $<h_{\min }$ & 100 & 39 \\
\hline \multicolumn{13}{|c|}{ Summer } \\
\hline 2004 & 1.938 & & & -2161 & 105 & $>h_{\max }$ & $\mathbf{0}$ & 2.030 & -2607 & $>h_{\max }$ & 0 & -446 \\
\hline 2005 & 1.864 & & & -2206 & 77 & $>h_{\max }$ & $\mathbf{0}$ & 1.858 & -2005 & $>h_{\max }$ & 0 & 201 \\
\hline 2006 & 1.833 & & & -2439 & 55 & $>h_{\max }$ & 0 & 1.858 & -2495 & $>h_{\max }$ & 0 & -56 \\
\hline 2007 & 1.821 & & & -2096 & 134 & $>h_{\max }$ & $\mathbf{0}$ & 1.858 & -2258 & $>h_{\max }$ & 0 & -162 \\
\hline 2008 & 1.785 & & & -2132 & 144 & $>h_{\max }$ & $\mathbf{0}$ & 1.776 & -2486 & $>h_{\max }$ & 0 & -354 \\
\hline 2009 & 1.754 & & & -2209 & 71 & $>h_{\max }$ & $\mathbf{0}$ & 1.776 & -2341 & $>h_{\max }$ & 0 & -132 \\
\hline 2010 & 1.722 & & & -1336 & 99 & $>h_{\max }$ & 0 & 1.776 & -1735 & $>h_{\max }$ & 0 & -399 \\
\hline 2011 & 1.693 & & & -2131 & 97 & $>h_{\max }$ & 0 & 1.692 & -2022 & $>h_{\max }$ & 0 & 109 \\
\hline 2012 & 1.659 & & & -2488 & 71 & $>h_{\max }$ & 0 & 1.656 & -2527 & $>h_{\max }$ & 0 & -39 \\
\hline 2013 & 1.620 & & & -1462 & 45 & $>h_{\max }$ & 0 & 1.656 & -1476 & $>h_{\max }$ & 0 & -14 \\
\hline
\end{tabular}

tions for winter balance and all measurement dates are shown in the Supplement of this paper.

Since the year 2013, the observational setup includes two AWS on and near the glacier and in spring 2014 a runoff gauge was installed $3 \mathrm{~km}$ down stream of the glacier terminus. Seasonal and annual mass balances are regularly submitted to the World Glacier Monitoring Service (WGMS) since the beginning of measurements in the year 2004.

\subsection{Meteorological data}

The mass balance model used in this study requires meteorological data as input. These data originate from AWS (1851 to 3325 ma.s.1.) in the vicinity of the glacier (Fig. 1) and were provided by the HOB. Hourly values of air temperature, relative humidity and global radiation were taken from the station Sulden Madritsch, 2825 ma.s.1., located in an alpine rock cirque some $2.5 \mathrm{~km}$ north of Langenferner. The other three required meteorological input variables are wind speed, 
precipitation and atmospheric air pressure. Those data were not available at Sulden Madritsch for the entire study period. Consequently wind speed data were taken from the station at Schöntaufspitze, 3325 ma.s.1., $5 \mathrm{~km}$ north of Langenferner. Air pressure was downscaled from ERA-Interim reanalysis data of the nearest surface grid point $\left(46.5^{\circ} \mathrm{N}, 10.5^{\circ} \mathrm{E}\right)$. Daily precipitation sums originate from the station at the dam of Zufritt reservoir, 1851 ma.s.l. in the Martell Valley, approximately $11 \mathrm{~km}$ northeast of the glacier (Fig. 1).

Since 2013 the Institute of Atmospheric and Cryospheric Sciences, University of Innsbruck (ACINN), operates two AWS at Langenferner. One station is drilled into the ice of the upper glacier part at an altitude of $3238 \mathrm{~m}$ a.s.l. and is designed to measure all meteorological parameters needed to calculate the glacier surface energy balance. The second station was installed on solid rock ground close to the middle part of the glacier serving as a robust back up to bridge possible data gaps of the ice station. Data of those two stations were used to derive spatial gradients and transfer functions of meteorological data, as well as to optimize the radiation scheme of the applied mass balance model.

\subsection{Digital terrain models (DTMs) from airborne laser scanning}

Data from three ALS campaigns were used for this study. Respective surveys were conducted around 14 September 2005, on 4 October 2011 and on 22 September 2013. For the area on and around Langenferner the point density of the 2005 and 2013 data sets is 1.06 and 2.65 points per $\mathrm{m}^{2}$, respectively, and the density of the 2011 data set is 2.84 points per $\mathrm{m}^{2}$. High-resolution $(1 \mathrm{~m})$ DTMs of the study area were calculated from the original ALS point data for all three data sets, where the mean value of all points lying in a raster cell was used as the elevation value for the cell and cells without measurements were interpolated from surrounding grid cells. For more details on the ALS data and resulting DTM the reader is referred to Galos et al. (2015).

\subsection{Glacier outlines from orthoimages, ALS and Global Navigation Satellite System (GNSS)}

Orthophotos from four acquisitions were used for updating the glacier area of Langenferner. Orthophotos for the years 2003, 2006 and 2008 were provided by the Autonomous Province of Bozen/Südtirol, while data for the year 2012 were available as a base map within Esri ArcGIS. The delineation of glacier area was done manually, which, for this small and well-known glacier, ensures the maximum accuracy. Outlines for the years 2005, 2011 and 2013 were derived from ALS data using high-resolution hill shades and DEM differencing following the approach of Abermann et al. (2010). This method also enabled the delineation of debriscovered glacier margins as areas which had undergone no change in surface elevation between two acquisition dates could be classified as ice-free while debris-covered ice was still subject to some lowering. However, debris cover is a minor issue at Langenferner since only a few percent of the lower glacier part are covered by debris. The glacier outline of 2010 was assessed from extensive differential GNSS measurements in early October 2010.

In the uppermost part of the glacier the outlines are confined by ice divides which were derived applying a watershed algorithm to the ALS DEM 2005. Although the glacier surface topography in this area changed during the observation period, the impacts on the glacier flow direction are negligible and the outlines of the uppermost glacier part were consequently kept constant throughout the study period.

\subsection{Snow line from terrestrial photographs and satellite images}

Information on snow cover extent was used to tune the mass balance model for individual points on the glacier. In order to map the evolution of the transient snow line at Langenferner during the ablation period, we made recourse of an extensive set of terrestrial and aerial images mainly recorded during the field campaigns on the glacier. We used photos from more than 70 field work campaigns, private visits and dated photographs from the internet. A small number of Landsat scenes from different dates provided additional information on the snow cover extent on the glacier. These data were used to manually determine the approximate date when the snow of the previous winter had melted entirely at each given stake location. In most cases the date of snowmelt could be determined with an estimated accuracy of \pm 5 days, and in many cases probably even better.

\section{Homogenization of data and methods}

\subsection{Point measurements}

Besides a sparse and unevenly distributed measurement setup during the first half of the study period affecting annual mass balances, the original record of winter balances was influenced by methodological inhomogeneities concerning the attribution of snow accumulation and ice ablation to the correct reference year or season. These problems have to be addressed in order to create a consistent and comparable record of annual and seasonal mass balance according to the fixed date system (e.g., Cogley et al., 2011).

\subsubsection{Stratigraphic correction of snow measurements}

Accumulation of snow or firn is measured by means of snow probings and snow pits. Both techniques record the entire snow pack down to a characteristic reference layer which is typically given by the ice surface at the end of the previous ablation season or the firn surface at the date of the last local mass minimum. Hence, there is a need to correct the snow 
depth measurements in spring for snow fallen during the previous hydrological year (i.e. before 1 October) in order to obtain values corresponding to the fixed date period. As part of the reanalysis process we accounted for this problem (which was not considered in the original analyses up to the year 2008) by subtracting the respective snow water equivalent, which for all years was measured at the stake locations at the end of the previous hydrological year.

\subsubsection{Ice ablation in the hydrological winter period}

While incorrect attribution of summer snow can affect both annual and seasonal mass balance, ice ablation in late autumn (after 30 September) only affects the seasonal mass balances. In most years of the study period ice ablation during late autumn at Langenferner was negligible since low elevated areas at the tongue are relatively small and receive only little insolation during that time of the year. Nevertheless, in October/November of the years 2004 and 2006 considerable melt took place in the middle and lower parts of Langenferner. While in the original analyses this issue was not considered, although stake data from late autumn field work were available, the point winter balances were corrected for late autumn ice melt during the reanalysis process.

\subsubsection{Fixed date versus floating date}

Measurements for annual mass balance were in all years carried out very close to end of the hydrological year and, if necessary, stratigraphic corrections for snow cover were applied. Hence original annual balances were reported as fixed date balances and thus no additional correction was applied during the reanalysis. Original winter mass balances on the contrary were calculated following the floating date approach, meaning that the water equivalent of the snow pack accumulated since the preceding summer was measured during a field campaign in the first half of May and no further corrections were applied. In order to make the results of the seasonal balances comparable, we calculated the fixed date winter mass balance by scaling the measured and corrected point values of winter balance in order to obtain the water equivalent of snow at the end of the hydrological winter season (30 April). This was done based on precipitation measurements at Zufritt reservoir and on the ratio of accumulated precipitation during the measurement period (floating date) and during the hydrological winter season (fixed date) as follows:

$b_{\mathrm{fix}}=b_{\mathrm{fld}} \cdot \frac{\sum P_{\mathrm{fix}}}{\sum P_{\mathrm{fld}}}$,

where $b_{\text {fix }}$ and $b_{\text {fld }}$ are the fixed date and floating date point values of winter balance and $\sum P_{\text {fix }}$ and $\sum P_{\text {fld }}$ are the precipitation sums recorded at Zufritt reservoir during the fixed date and the floating date period, respectively. Note that this approach is based on the assumption that no meltwater drains from the glacier during the hydrological winter period, which is a reasonable assumption for Langenferner (see Supplement for a more detailed discussion).

\subsection{Point mass balance modeling}

A major shortcoming of the original mass balance record at Langenferner is the lack of observation points in the upper glacier part during the first years of the study period. This affects the calculations of annual mass balance in the early observation years and the temporal consistency of the record. Therefore, a central aim of this study was to create a spatially and temporally consistent set of point annual mass balance. To achieve this we generated artificial measurement points in the poorly represented upper glacier section by applying a physically based energy and mass balance model (Mölg et al., 2012). We have chosen a physical approach since reconstructions based on the spatial or temporal transfer of known mass balance gradients or altitudinal profiles (e.g., Carturan et al., 2009; Kuhn et al., 2009) often show limited performance. More comprehensive statistical approaches such as presented by Lliboutry (1974), Thibert and Vincent (2009) or Eckert et al. (2011) were not applicable due to the short series of available data (at some locations 5 years or less). However, the performance of modern model approaches is generally expected to be superior to statistical approaches. This is due to the integration of additional information such as the influence of local topography and related implications on governing micro-climatological parameters like temperature and radiation, snow line, snow depth and density, etc., which enables a more accurate calculation of the local mass balance. In contrast, statistical methods damp the spatiotemporal variability of mass balance as they imply (linear) correlation between measurement points or glacier parts. Nevertheless, the use of models driven with meteorological data in glacier mass balance series can be problematic (see Sect. 5.4). For this reason we clearly flag all results related to modeling and provide full methodical transparency in order to enable possible data users to decide whether the data suit their purpose or not.

The applied model was run in its point configuration as the purpose of this study is not to use a model for the spatial extrapolation of point measurements on the glacier-wide scale as done in a number of other studies (Huss et al., 2013; Barandun et al., 2015; Kronenberg et al., 2016; Sold et al., 2016) but is rather to reproduce a best possible estimate of annual balance values for point locations where ablation stakes were placed in the subsequent years. In this configuration, the model performance can be validated directly using data from available stake measurements. A spatially distributed model setup would introduce larger errors regarding the mass balance at selected points, while the point model allows for a spatially flexible model tuning and strongly reduces errors due to shortcomings in the spatial extrapolation of meteorological variables (e.g., Carturan et al., 2015; 
Sauter and Galos, 2016; Shaw et al., 2016) and the choice of the optimal parameter setting (e.g., MacDougall and Flowers, 2011; Gurgiser et al., 2013). The application of a relatively complex physical model is justified by the dominant influence of local topographic factors on micro-meteorological variability and the resultant large spatial variability of the surface mass balance, which can only be resolved in a sufficient way by a process-based model. Furthermore, we aim to create a set of homogenized point mass balances in addition to glacier-wide balances, since point balances have proven to be valuable information sources for investigations on glacierclimate interactions (e.g., Huss and Bauder, 2009).

\subsubsection{Transfer of meteorological variables}

Although our study does not aim to explicitly resolve individual energy fluxes, we extrapolated meteorological variables using techniques which have also been applied in processoriented studies since insufficient extrapolation of meteorological input data is often a dominant error source in the application of physical glacier mass balance models (e.g., Gurgiser et al., 2013; Shaw et al., 2016; Sauter and Galos, 2016). The extrapolation techniques used here were optimized using data from the on-glacier weather station in the upper part of the glacier for the period July 2013 to August 2015, a period when measurements at all AWS were available. Air temperature from Sulden Madritsch was extrapolated to the glacier applying an altitudinal lapse rate of $6.5 \times 10^{-3} \mathrm{~K} \mathrm{~m}^{-1}$ and an offset of $-0.56 \mathrm{~K}$, reflecting the different micro-climates over rock (Sulden Madritsch) and the on-glacier station. Both values were derived from a linear regression between measurements at Madritsch and the glacier station during the summers 2013 and 2014. Relative humidity was corrected for saturation over ice for below-freezing temperatures but the data were not further modified since no clear spatial pattern was detectable in the analyzed data sets. Global radiation was used to calculate a cloud factor (e.g., Mölg et al., 2009b; Haberkorn et al., 2015) which was assumed to be spatially constant over the study area. This factor was used to drive the radiation scheme of the mass balance model which was optimized for the glacier using short- and long-wave radiation data from the glacier. Wind speed from Schöntaufspitze was linearly scaled to match observed wind speeds at the glacier station using a scaling factor of 0.67. ERA-Interim atmospheric air pressure from the nearest surface grid point $\left(46.5^{\circ} \mathrm{N}, 10.5^{\circ} \mathrm{E} ; 8.5 \mathrm{~km}\right.$ from the glacier) was reduced to the altitude of the stake locations by the barometric equation; since the mass balance model is relatively insensitive to small changes in air pressure, the temporal resolution of $1 \mathrm{~h}$ was achieved by linear interpolation of the 6-hourly reanalysis data. Daily precipitation sums measured at Zufritt reservoir (1851 ma.s.1., $11 \mathrm{~km}$ from the glacier) were used to assess hourly precipitation at the glacier, whereby the daily sums were temporally redistributed according to the course of relative humidity during the measurement day. Precipita- tion was only assigned to time steps when humidity exceeded the threshold of $93 \%$ and the amount for a single time step was then scaled according to the magnitude of exceedance. If this threshold was not reached throughout the day but precipitation was measured, the threshold was lowered by steps of $5 \%$. This procedure was found to have a remarkable positive impact on the model performance. The sensitivity of modeled point mass balance to this correction can easily reach about $\pm 100 \mathrm{~kg} \mathrm{~m}^{-2}$ on the annual scale compared to a model driven with daily precipitation sums equally distributed over $24 \mathrm{~h}$.

\subsubsection{Monte Carlo optimization of model parameters}

The mass balance model approach was set up as follows (Fig. 3): first the model was precalibrated applying realistic values for the model parameters which were either taken from the literature or from direct meteorological observations in the study area. The first-guess model precipitation $P_{0_{\text {model }}}$ was generated applying a precipitation scaling factor $\Gamma_{0}$ to the measured and temporally redistributed record of Zufritt $P_{\text {obs.red. }}$ in order to fit the model to the observed values of winter mass balance (Eq. 2).

$P_{0_{\text {model }}}=P_{\text {obs.red }} \cdot \Gamma_{0}$

This precalibration was done for the location of stake 22 (Fig. 4), a stake situated in the upper glacier part, in the center of the area where the point modeling was carried out. This stake was chosen as the relatively homogeneous surrounding makes it representative for a wider region of the glacier and it offers by far the highest number of stake readings in the upper region of Langenferner. It is hence the best choice for the optimization of model parameters, which was done applying a Monte Carlo approach (e.g., Machguth et al., 2008; Mölg et al., 2012) performing 1000 model runs with different parameter combinations in order to find the best model setting for the local conditions. The optimal parameter combination was then applied to all stake locations in the upper glacier part. An individual Monte Carlo optimization for each stake was not possible due to the low number of available readings at some stakes.

\subsubsection{Model tuning for individual stakes and years}

Large uncertainties in process-based studies of glacier mass balance are commonly related to accumulation and its spatial distribution: altitudinal precipitation gradient, redistribution of snow due to wind and its large influence on spatial accumulation patterns, the temporal evolution of surface albedo and hence net radiation, etc. (e.g., Gurgiser et al., 2013; Machguth et al., 2008). In order to minimize respective uncertainties in the mass balance model, we made recourse of a calibration procedure which integrates available snow information. For this purpose, the mass balance model with the optimized parameter setting was tuned by replacing 


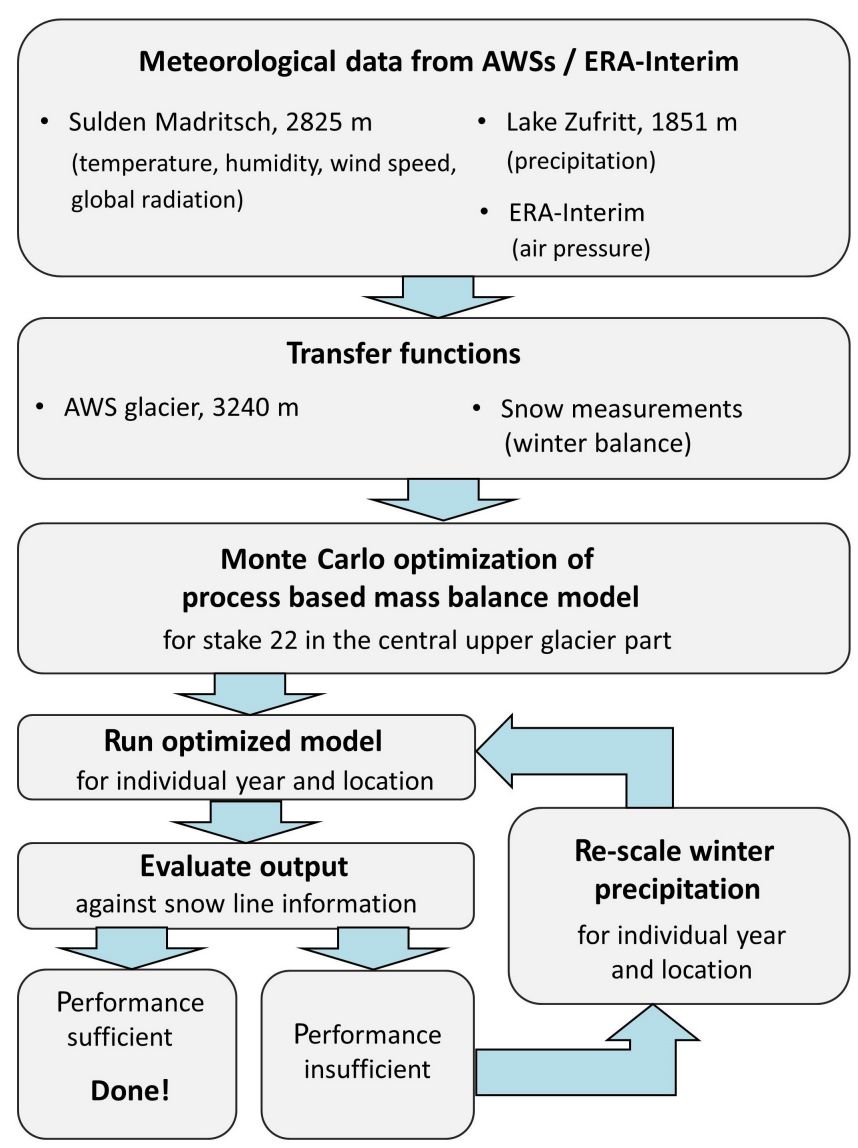

Figure 3. Schematic flow-chart illustrating the applied model approach.

$\Gamma_{0}$ in Eq. (2) by the individual (for stake $i$ and year $a$ ) scaling factor $\Gamma_{i, a}$, which accounts for all site-specific properties related to accumulation. $\Gamma_{i, a}$ should hence not be seen as a precipitation scaling factor but rather as a way to correct for the unresolved accumulation processes listed above. These processes are highly variable in space and time, and therefore $\Gamma_{i, a}$ is allowed to vary freely, ensuring a high model skill as it enables the model to account for the full spectrum of natural mass balance variability (see Sect. 5.1). This stake and year individual tuning procedure was performed in a way that the observed date of the emergence of the ice surface at the respective location was correctly reproduced by the model. An automated iterative approach ensured that the modeled date did not differ by more than 1 day from the observed date.

Note that the present approach is not applicable in years with a persisting snow cover at the stake location. But during the first observation years (2004 to 2008) when measurements were partly missing, annual mass balances at Langenferner were very negative and accumulation at the end of the year was restricted to a few percent of the glacier area. For the few years and stakes with missing measurements and snow cover persisting throughout the ablation season, $\Gamma_{i, a}$ was derived based on linear regression with $\Gamma_{i}$ series of neighboring stakes. Values for $\Gamma_{i, a}$ vary in the range of 1.1 to 4.7 (Fig. 5), and curvature of the terrain and other wind related factors are clearly reflected in the spatial $\Gamma_{i, a}$ patterns, while interannual variability seems to be determined by meteorological phenomena, such as number and strength of storm events, dominant flow direction during the accumulation period or the absolute amount of accumulation since years with lower accumulation amounts tend towards larger $\Gamma_{i, a}$ values.

\subsection{Spatial integration of point data}

Five different methods were applied to spatially integrate the reanalyzed values of annual and winter point mass balance in order to obtain mean specific glacier-wide balances. We applied the traditional contour line method in two different ways and additionally made recourse of three automatic methods in order to assess and investigate possible differences and uncertainties due to the applied analysis method. After the individual extrapolation of point measurements, all applied methods calculate the total mass change $\Delta M$ by spatial integration of the specific mass change $b$ over the area $S$ based on the following equation:

$$
\Delta M=\int_{S} b \cdot d S .
$$

The mean specific mass balance $B$ is then calculated as follows:

$B=\frac{\Delta M}{S}$.

Equations (3) and (4) can be applied to the entire glacier area to obtain the glacier-wide specific glacier mass balance or to each single $50 \mathrm{~m}$ altitude band to calculate the altitudinal mass balance profile and subsequently the equilibrium line altitude (ELA). The latter is calculated as the lower most intersection of the altitudinal mass balance profile with the $b=0$ axis (Cogley et al., 2011). While annual $\left(B_{\mathrm{a}}\right)$ and winter $\left(B_{\mathrm{w}}\right)$ mass balances are based on measurements, summer mass balances are calculated as a residual:

$B_{s}=B_{\mathrm{a}}-B_{\mathrm{w}}$

For comparisons with the geodetic method there is the need for direct glaciological balances over the geodetic survey period. These are calculated summing up the annual glaciological mass changes $\left(\Delta M_{\mathrm{a}}\right)$ from the beginning $\left(t_{0}\right)$ to the end $\left(t_{1}\right)$ of the period of record (PoR) and dividing the result by the average glacier area $S$ during that period (Eq. 6).

$B_{\text {glac.PoR }}=\frac{\sum_{t_{0}}^{t_{1}} \Delta M_{\mathrm{a}}}{\frac{1}{2} \cdot\left(S_{t_{0}}+S_{t_{1}}\right)}$

\subsubsection{Contour-line-based extrapolations}

The contour line method (e.g., Østrem and Brugman, 1991) is an often used approach for the determination of glacier 


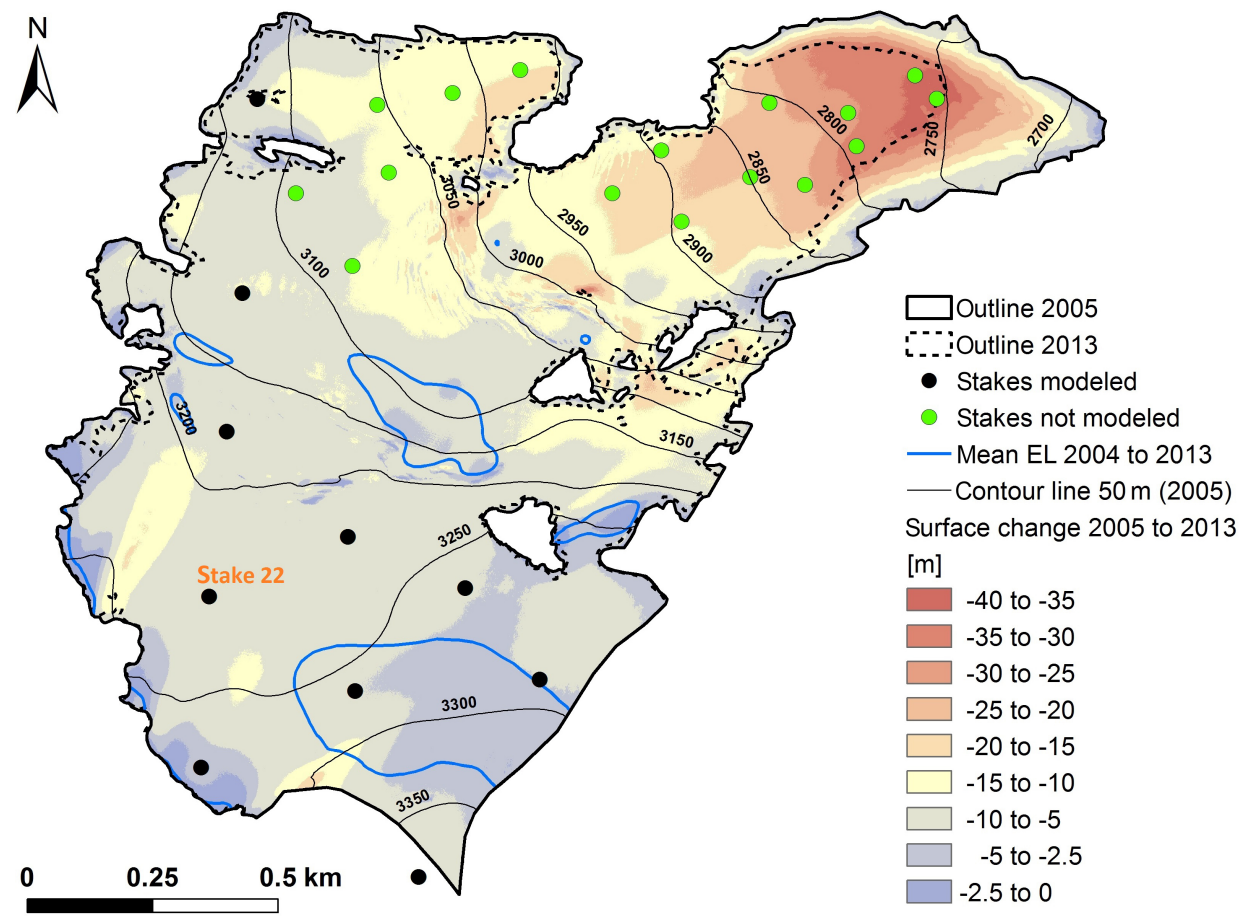

Figure 4. ALS-derived surface elevation change at Langenferner for the period September 2005 to September 2013. Also shown are the stakes used for the automatic extrapolation schemes, where black dots refer to locations to which the mass balance model was applied. The blue line indicates the equilibrium line at the end of the hydrological years averaged over the study period.

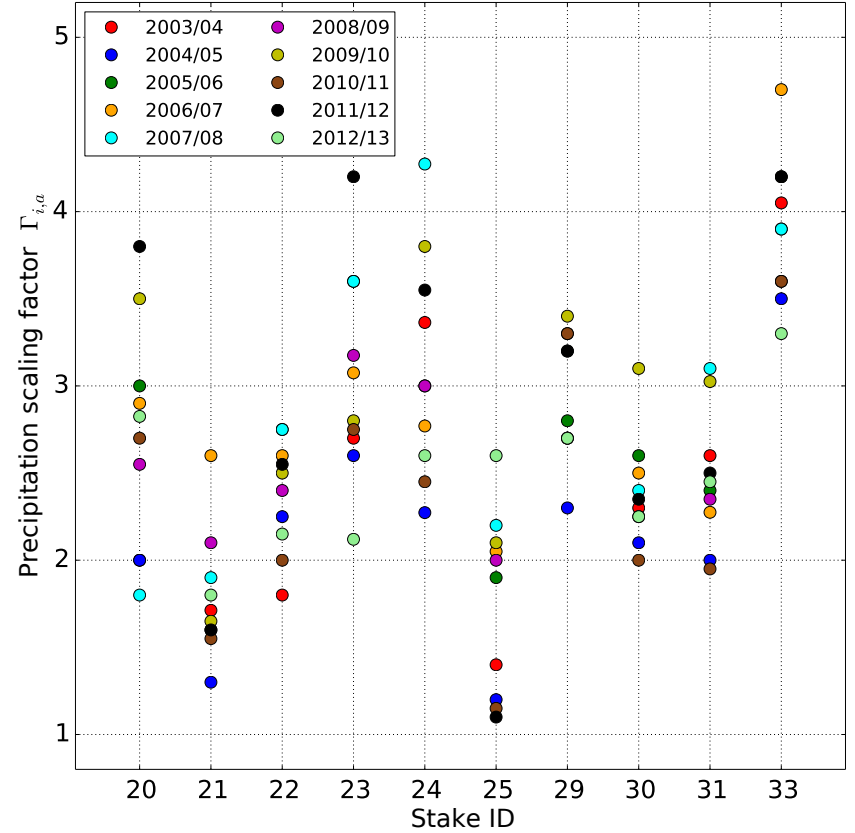

Figure 5. Precipitation scaling factors $\Gamma$ for different locations $(i)$ and years $(a)$. mass balance. It is based on manually derived lines of equal mass balance based on point measurements and has the advantage that the spatial pattern of surface mass change is relatively well reflected in the analysis if the method is applied thoroughly. The manual generation of contour lines often incorporates the integration of further observational information such as the position of the snow line, date of ice emergence at individual locations, meteorological conditions on the glacier and other expert knowledge such as typical spatial patterns. This kind of information is difficult to capture in a purely objective or mathematical sense, nevertheless it often enhances the quality of the results and the spatial resolution of mass balance information.

Mass balance contour lines are then used to derive areas of equal mass balance where the mean value of the contour lines is assigned to the area between the lines. However, for this study we applied the contour line method in two different ways: once in its purely traditional form creating areas of equal mass balance between the manually drawn contour lines of $250 \mathrm{~kg} \mathrm{~m}^{-2}$ equidistance, and once applying the Esri ArcGIS interpolation tool topo to raster, which is based on the ANUDEM algorithm (e.g., Hutchinson, 2008; Hutchinson et al., 2011), to the hand-drawn and digitized contour lines and the set of reanalyzed point values. The latter method results in mass balance rasters with a $1 \times 1 \mathrm{~m}$ resolution which were subsequently spatially integrated to obtain the mean specific mass balance (Eqs. 3 and 4). 


\subsubsection{Automatic extrapolations}

In contrast to the contour-line-based analyses, automatic extrapolation methods avoid subjective influences, are fast and relatively simple to apply but are subject to restrictions in realistically reproducing the spatial distribution of surface mass balance. We apply three fully automatic extrapolation procedures: (i) the profile method based on a linear regression of point measurements with altitude and the areaaltitude distribution of the glacier (e.g., Escher-Vetter et al., 2009), (ii) the automatic extrapolation applying the topo to raster function and (iii) an inverse distance weighting procedure. While the contour-based methods were applied making recourse of all available information for the respective year, the three automatic methods were based on a reduced but temporally consistent set of reanalyzed point measurements which in this context means that the number and position of the measurement points used in the calculations was kept (almost) constant. This was done in order to avoid noise related to changes in the measurement setup affecting the temporal mass balance signal. For winter balances the creation of a consistent set of point values was not possible due to large year-to-year differences in amount and spatial distribution of measurements.

\subsection{Geodetic mass balance calculations}

The geodetic mass balance of Langenferner for the period 2005 to 2013 and the subperiods 2005 to 2011 and 2011 to 2013 was calculated based on differencing high-resolution (1 m) DEMs from ALS data (Abermann et al., 2010) of the respective years. The total volume change $\Delta V$ was calculated by integrating the elevation change $\Delta h$ at the individual pixel $k$ of length $r$ of the co-registered DEMs following Zemp et al. (2013):

$\Delta V=r^{2} \cdot \sum_{k=1}^{K} \cdot \Delta h_{k}$.

Subsequently the derived volume change was converted to a geodetic mass balance over the period of record following Eq. (8):

$$
B_{\text {geod.PoR }}=\frac{\Delta M_{\text {geod }}}{\bar{S}}=\frac{\Delta V \cdot \bar{\rho}}{\frac{1}{2} \cdot\left(S_{t_{0}}+S_{t_{1}}\right)},
$$

where $\bar{\rho}$ denotes a mean glacier density of $850 \pm 60 \mathrm{~kg} \mathrm{~m}^{-3}$ as proposed by Huss (2013) and $\bar{S}$ is the mean glacier area between the two acquisition dates calculated as the mean of the extents at the beginning and the end $\left(S_{t_{0}}\right.$ and $\left.S_{t_{1}}\right)$ of the PoR.

\subsubsection{Corrections for snow cover and survey date}

The results of the geodetic surveys were corrected for differences in snow cover between the acquisition dates as follows:

$$
\begin{aligned}
\Delta M_{\text {geod.corr }} & =\Delta M_{\text {geod }}+\left(\bar{h}_{s_{t_{0}}} \cdot \bar{\rho}-\bar{h}_{s_{t_{0}}} \cdot \bar{\rho}_{s_{t_{0}}}\right) \\
& -\left(\bar{h}_{s_{t_{1}}} \cdot \bar{\rho}-\bar{h}_{s_{t_{1}}} \cdot \bar{\rho}_{s_{t_{1}}}\right),
\end{aligned}
$$

where $\Delta M_{\text {geod.corr }}$ denotes the geodetically derived mass change corrected for snow cover differences between the two acquisition dates $t_{0}$ and $t_{1}, \Delta M_{\text {geod }}$ is the uncorrected mass change, $\bar{h}_{\mathrm{s}}$ denotes the mean snow depth (at dates $t_{0}$ and $t_{1}$, respectively), $\bar{\rho}$ the bulk glacier density and $\bar{\rho}_{\mathrm{s}}$ the mean snow density at the acquisition dates $t_{0}$ and $t_{1}$.

In 2005, no field measurements were performed close to the ALS survey date. But field data from 4 September 2005 in combination with meteorological records of nearby AWS, as well as photographs from nearby glaciers, indicate that there was basically no snow cover at the date of the 2005 ALS campaign. Seasonal snow was hence regarded as negligible for glacier-wide analyses in 2005. In 2011, in situ measurements were performed on 30 September, 4 days prior to the ALS campaign. Despite the short time difference between direct and geodetic measurements, we applied a correction of the measured snow depths due to relatively warm weather conditions in this period. For this purpose, the (optimized but untuned) mass balance model was initialized at all ablation stakes and a few additional locations using the measured snow depths and densities of 30 September as initial condition. In 2013, extensive direct measurements were carried out simultaneously to the ALS campaign on 23 September to quantify the high amount of snow and firn in this year.

Survey date corrections were based on modeled mass change during the periods between ALS survey and direct measurements in the years 2005 and 2011, while in 2013 the correction was based on direct measurements performed on 23 and 30 September. Point values of snow and mass change were extrapolated using topo to raster to calculate glacierwide mean values for the individual properties. Mean specific mass changes (representing corrections for snow cover and survey date, respectively) were finally added (subtracted) to (from) the geodetically derived mass change over the survey period.

\subsection{Annual glacier topographies and outlines}

Changes in glacier area and topography may have significant impacts on the mass balance of mountain glaciers through various feedbacks (e.g., Paul, 2010; Huss et al., 2012) and since respective data are used as input for glacier models, they constitute glaciological key information. Hence, there is a need to frequently update topographic reference data used in mass balance calculations (e.g., Zemp et al., 2013, 2015). Langenferner was subject to remarkable hypsometry changes 
during the study period (Figs. 4 and 6). While glacier outlines for the current study could be directly derived from orthophotos or ALS data for all years except for 2004, 2007 and 2009 , data on glacier topography are only available through the three ALS campaigns. In order to minimize the effect of outdated area and hypsometry we calculated annual glacier outlines and topographies by combining the available set of related data with the fields of reanalyzed annual surface mass balance. Doing so we consider the change in surface elevation $\Delta h$ at one location (pixel) $k$ of the glacier over the time period $t$ as the result of the following terms:

$\Delta h_{k, t}=\Delta h_{\text {surf }_{k, t}}+\Delta h_{\mathrm{dyn}_{k, t}}+\Delta h_{\mathrm{basal}_{k, t}}$,

where $\Delta h_{\text {surf }_{k, t}}$ denotes the surface elevation change related to surface mass balance, $\Delta h_{\mathrm{dyn}_{k, t}}$ represents the surface change due to glacier dynamics and $\Delta h_{\text {basal }_{k, t}}$ is the surface-change-related basal (and internal) processes. As the latter term is assumed to be relatively small on the glacierwide scale (e.g., Cuffey and Paterson, 2010), it is neglected. The rasters of spatially extrapolated surface mass balance for each year (Sect. 3.3.1) and those referring to snow and date corrections (Sect. 3.4.1) can be summed up for the time period between the two geodetic surveys in order to calculate the term $\Delta h_{\text {surf }_{k, t}}$. Consequently, $\Delta h_{\mathrm{dyn}_{k, t}}$ for the respective period can be calculated as follows:

$$
\begin{aligned}
\Delta h_{\mathrm{dyn}_{k, t}} & =\Delta h_{k, t}-\sum_{t_{0}}^{t_{1}} \Delta h_{\text {surf }_{k, t}} \\
& =\left(h_{k, t_{1}}-h_{k, t_{0}}\right)-\sum_{t_{0}}^{t_{1}} \Delta h_{\text {surf }_{k, t}},
\end{aligned}
$$

where $h_{k, t_{0}}$ and $h_{k, t_{1}}$ are the surface elevations at the pixel $k$ given by the DEMs taken at date $t_{0}$ and $t_{1}$, respectively, and $\sum_{t_{0}}^{t_{1}} \Delta h_{\text {surf }} k_{k, t}$ refers to the temporally integrated elevation change due to surface mass balance. Due to the absence of data on the temporal evolution of glacier flow velocity, we assume the rate of $\Delta h_{\mathrm{dyn}_{k}}$ to be temporally constant during the observation period. This simplifies the calculation of the annual $\Delta h_{\mathrm{dyn}_{k, a}}$ to

$\Delta h_{\mathrm{dyn}_{k, a}}=\frac{\Delta h_{\mathrm{dyn}_{k}}}{d_{\mathrm{PoR}}}$,

where $d_{\mathrm{PoR}}$ is the duration of the observation period in years. The result is a raster of $\Delta h_{\mathrm{dyn}_{k, a}}$ which can be applied to all the observation years. The surface elevation of a certain year $h_{k, a}$ can finally be calculated by adding the surface elevation change due to surface mass balance in the respective year $a$ and the annual change related to glacier dynamics to the surface elevation of the previous year $h_{k, a-1}$ (Eq. 13).

$h_{k, a}=h_{k, a-1}+\Delta h_{\mathrm{surf}_{k, a}}+\Delta h_{\mathrm{dyn}_{k, a}}$

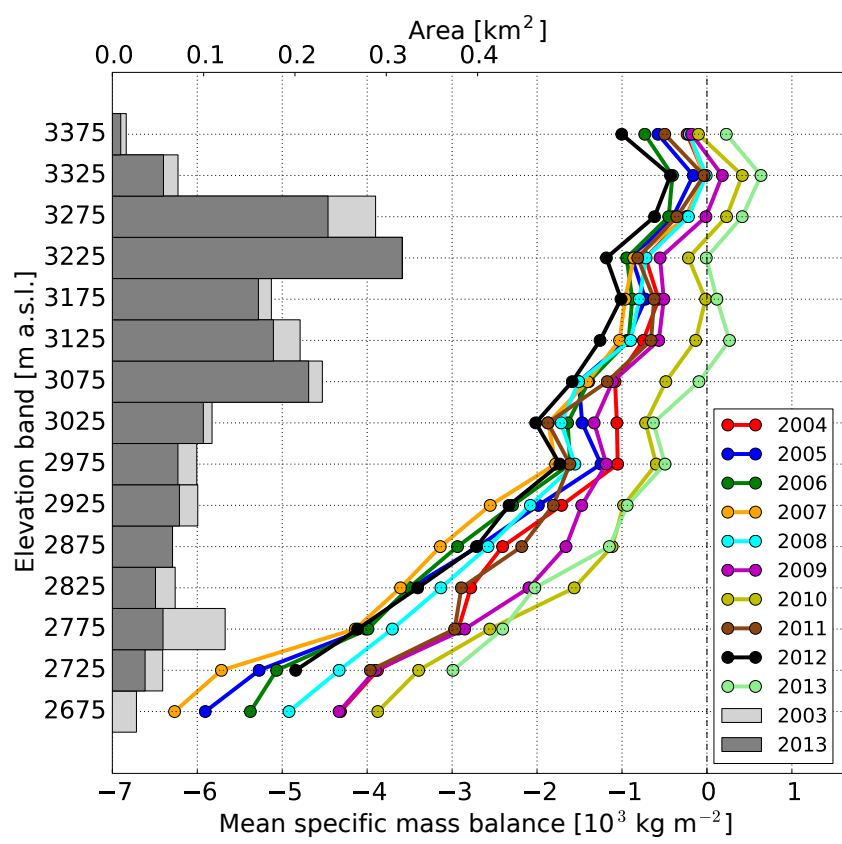

Figure 6. Altitudinal distribution of reanalyzed annual mass balances as well as of the glacier surface area at the beginning (2003) and the end of the study period (2012).

The DEM taken at the end of the observation period served as a boundary condition for surface elevation at areas which became ice-free during the observation period in a way that all raster cells in those areas showing a surface height smaller than the surface of the ice free topography are set back to the value of the latter. Glacier outlines were derived by identifying ice-free pixels as having undergone no change in surface elevation.

Note that the term $\Delta h_{\mathrm{dyn}_{k, a}}$ represents all the differences between the direct surface measurements and geodetically detected surface changes. These are not only differences which can be associated with glacier dynamics but also shortcomings in the spatial extrapolation of surface mass balance measurements and changes due to internal or basal processes. This problem does not affect the temporally integrated topography change but may lead to additional errors regarding annual surface topographies. Nevertheless, this simple method provides a possibility to annually update the reference area and topography used in the mass balance calculations and hence represents a useful tool for areas with large changes in surface elevation.

\section{Uncertainty assessment}

In order to enhance the value of the reanalyzed mass balance record, a detailed error assessment was performed following the recommendations of Zemp et al. (2013). We categorized potential errors in the measurements and analyses into ran$\operatorname{dom}(\sigma)$ and systematic $(\epsilon)$ errors. In the subsequent sections 
we discuss the origin of such errors related to the methods applied and explain how they were assessed. Thereby we primarily focus on random uncertainties, since systematic errors are difficult to quantify in the absence of an absolute reference for validation. In order to detect an eventually significant systematic bias in the reanalyzed record of annual balance, we finally perform a comparison of directly measured mass changes to those obtained by the geodetic method. The individual error sources and the respective numbers used in the uncertainty model are listed in the Supplement of this paper.

\subsection{Uncertainties of glaciological measurements}

Uncertainties in glaciological mass balances may originate from various sources and can be categorized into errors in point measurements, errors related to spatial extrapolations of point measurements and errors due to inaccurate or outdated glacier extents (Zemp et al., 2013). The random error of the mean specific mass balance for an individual year $\left(\sigma_{\text {glac.total.a }}\right)$ can consequently be formulated as follows:

$\sigma_{\text {glac.total.a }}=\sqrt{\sigma_{\text {glac.point.a }}^{2}+\sigma_{\text {glac.spatial.a }}^{2}+\sigma_{\text {glac.ref.a }}^{2}}$

where $\sigma_{\text {glac.point.a }}$ is the error due to uncertainties on the point scale, $\sigma_{\text {glac.spatial.a }}$ represents errors related to spatial extrapolations and $\sigma_{\text {glac.ref.a }}$ accounts for uncertainties due to inaccurate glacier outlines. In this formulation $\sigma_{\text {glac.point.a }}$ is often misinterpreted since it does not represent the typical value of point scale errors but the uncertainty of glacier-wide mass balances related to the propagation of point uncertainties after the extrapolation of measurements. This term depends not only on the magnitude of point uncertainties but also on the number and spatial distribution of point measurements. Hence, it requires thorough evaluation (Sect. 4.1.1).

\subsubsection{Uncertainties related to point measurements}

Random errors on the point scale mainly originate from inaccurate readings. This involves ablation and accumulation measurements equally. For ablation stakes the respective error is on the order of 2 or $3 \mathrm{~cm}$. Limited representativeness of an ablation stake due to surface roughness is not really an error on the point scale but can introduce errors to the analysis when the data are extrapolated to larger areas. At Langenferner such surface features are typically $\leq 20 \mathrm{~cm}$ in height, although after long periods of exceptionally strong melt, surface structures were observed to reach the order of 30 to $50 \mathrm{~cm}$ in the lowest sections of the glacier.

For accumulation measurements the error potential is generally higher. Snow pits with measurements of snow depth and density offer the highest accuracy $\left(\approx 50 \mathrm{~kg} \mathrm{~m}^{-2}\right)$. But the number of snow pits is often kept low, as they are labor intensive and time consuming. Snow probings are somewhat less accurate since they are affected by instrument tilt, by uncertainties in the spatial extrapolation of snow density and by possible difficulties in the determination of last summer's reference surface. The latter effect can lead to large errors on the point scale but is assumed to play a minor role in this study since most "outliers" could be identified due to the high number of probings in combination with snow pit information.

However, the impact of uncertainties in point measurements on glacier-wide calculations depends on the number of point measurements and their spatial distribution. To quantify this problem, we applied a bootstrap approach (e.g. Efron, 1979) in which random errors according to a defined normal distribution were applied to all available individual point measurements before calculating the glacier-wide balance 5000 times for each case using the inverse distance weighting method for extrapolation. The respective annual uncertainties are then given by the standard deviation of the 5000 runs and range from 11 to $26 \mathrm{~kg} \mathrm{~m}^{-2}$ for annual balances and from 7 to $16 \mathrm{~kg} \mathrm{~m}^{-2}$ for winter balances.

\subsubsection{Uncertainties in the extrapolation of point measurements}

Similar to the propagation of point scale uncertainties, uncertainties related to the applied extrapolation method are also dependent on the number and distribution of point measurements, as well as on spatial balance patterns of the individual year or season. We assessed those uncertainties based on the analysis of the glacier-wide reanalyzed mass balances obtained from the five extrapolation methods used. The annual extrapolation uncertainty in our study is finally represented by the absolute range of the bias corrected results ranging from $23 \mathrm{~kg} \mathrm{~m}^{-2}$ (2006) to $134 \mathrm{~kg} \mathrm{~m}^{-2}$ (2008). Respective values for winter vary between $31 \mathrm{~kg} \mathrm{~m}^{-2}$ (2013) and $95 \mathrm{~kg} \mathrm{~m}^{-2}$ (2004). Note that for winter balances we used the range without bias correction $\left(r_{\mathrm{Brea}}\right)$ since the biases between the individual extrapolation methods were small and their origin could not be unequivocally explained.

\subsubsection{Uncertainties due to inaccurate glacier outlines}

Since for this study we make use of annual glacier outlines derived from orthophotos or ALS or calculated as described in Sect. 3.5, our analyses are not systematically affected by this issue. Hence the remaining uncertainties related to this problem are given by the random uncertainties of the annual glacier areas. We estimated the related standard error to be $15 \mathrm{~kg} \mathrm{~m}^{-2}$. For the year 2005 we applied a more conservative estimate of $25 \mathrm{~kg} \mathrm{~m}^{-2}$, since the reference area for this year suffers from larger uncertainties as it was derived by manually updating the 2003 glacier extent with a few GNSS points taken in 2004.

\subsection{Uncertainties in geodetic mass balances}

Uncertainties in the geodetic mass balance are mainly related to two problems: (i) errors in the used DEMs and (ii) uncer- 
tainties related to the conversion of the observed surface elevation changes to changes in mass. The overall random error of the corrected geodetic mass balances can be expressed as

$\sigma_{\text {geod.corr }}=\sqrt{\sigma_{\text {geod.total }}^{2}+\sigma_{\mathrm{dc}}^{2}+\sigma_{\mathrm{sc}}^{2}+\sigma_{\mathrm{sd}}^{2}}$,

where $\sigma_{\text {geod.total }}$ refers to the remaining uncertainties related to geodetic measurements after all applied corrections such as co-registration etc., $\sigma_{\mathrm{dc}}$ is the error related to density conversion, $\sigma_{\mathrm{sc}}$ refers to the error due to snow cover and $\sigma_{\mathrm{sd}}$ is the remaining error due to different survey dates compared to the glaciological method. Note that Eq. (15) differs from Eq. (18) in Zemp et al. (2013) in two points: firstly we split the uncertainties related to bulk glacier density and those introduced by differences in snow cover between the two survey dates. This is done because the available set of data allows for a sound quantification of snow cover. Secondly, we do not include the impacts of basal and internal processes since they neither represent an error in geodetic mass balance calculations nor could be quantified in a sufficient matter in the frame of the current study. Nevertheless we discuss those effects in Sect. 5.7.

\subsubsection{Uncertainties in ALS measurements}

To minimize systematic errors in the geodetic analysis, the co-registration of the three ALS data sets was tested using the pitched roofs of six buildings belonging to three mountain huts in the vicinity of Langenferner (Zufallhütte, Rifugio Casati and Marteller Hütte). Following Joerg et al. (2012), the inclined roof surfaces enabled us to check the data for a possible horizontal shift. However, no significant aspectdependence of DEM differences could be detected in the data sets used for this study. The vertical error due to uncertainties in the DEMs and spatial auto-correlation $\sigma_{\text {geod.total }}$ for the individual survey periods was tested by calculating the surface differences in stable reference areas outside the glacier. The surface difference in those areas is below $\pm 0.1 \mathrm{~m}$ for terrain with a slope angle below $40^{\circ}$. Since there are hardly any areas with slope angles of $40^{\circ}$ or more at Langenferner, we used $0.15 \mathrm{~m}$ as an upper threshold of possible vertical errors over the glacier area.

\subsubsection{Uncertainties related to glacier density}

In our study uncertainties related to unknown mean glacier density are reflected by the applied density range of $850 \pm 60 \mathrm{~kg} \mathrm{~m}^{-3}$ (Huss, 2013). Based on the knowledge about the study area, such as the typical size of the accumulation area and the absence of large crevasse zones, we estimate the real near-surface glacier density in the absence of seasonal snow to be in the range of 850 to $880 \mathrm{~kg} \mathrm{~m}^{-3}$.

\subsubsection{Uncertainties due to snow cover and survey date differences}

Uncertainties due to differences in snow cover at the two acquisition dates are difficult to estimate but we assume that they are quite small after we applied respective corrections (Sect. 3.4.1). Similar is true for uncertainties related to different acquisition dates between geodetic and glaciological surveys. Especially for the two longer periods (2005 to 2013 and 2005 to 2011), due to the drastic mass loss both errors are at least 1 order of magnitude smaller than the uncertainties related to the used bulk glacier density and are hence of minor importance. However, the respective errors for both problems were estimated as $100 \mathrm{~kg} \mathrm{~m}^{-2}$ for all (sub) periods.

\subsection{Method comparison}

In order to check the reanalyzed record of annual mass balance for a significant systematic bias, we compare the results for the period 2005 to 2013 to the mass change inferred using the geodetic method. Doing so, it has to be considered that the two methods are subject to generic differences since the glaciological method only captures (near) surface mass changes, while the geodetic approach also detects volume (and mass) changes due to internal and basal processes. Consequently, we avoid using the term "validation" for the methodological cross-check. Especially since we omit the explicit consideration of the abovementioned processes due to the fact that respective estimates without related measurements are speculative. However, method comparisons were performed for the period 2005 to 2013, as well as for the subperiods 2005 to 2011 and 2011 to 2013.

After applying the corrections described in Sect. 3.4.1, the reduced discrepancy $\delta$ (Zemp et al., 2013) between the two methods can be calculated as

$\delta=\frac{\Delta \mathrm{PoR}}{\sigma_{\text {common.PoR }}}=\frac{B_{\text {glac.PoR }}-B_{\text {geod.PoR }}}{\sqrt{\sigma_{\text {glac.PoR }}^{2}+\sigma_{\text {geod.PoR }}^{2}}}$.

Agreement between the two methods can be assumed within the $95 \%(90 \%)$ confidence interval if $|\delta|<1.96(|\delta|<$ 1.64). See Zemp et al. (2013) for a detailed description of this test.

\section{Results and discussion}

\subsection{Modeled annual point mass balance}

Overall, 80 values of annual point mass balances were calculated using the presented model approach. For 33 of those cases field measurements are available which allows for independent validation of the applied approach, yielding a root mean square deviation (RMSD) of $128 \mathrm{~kg} \mathrm{~m}^{-2}$ and a $R^{2}$ of 0.96 between modeled and measured values (Fig. 7). The magnitude of this error is similar to the uncertainty of glaciological point measurements reported in the literature (e.g., 


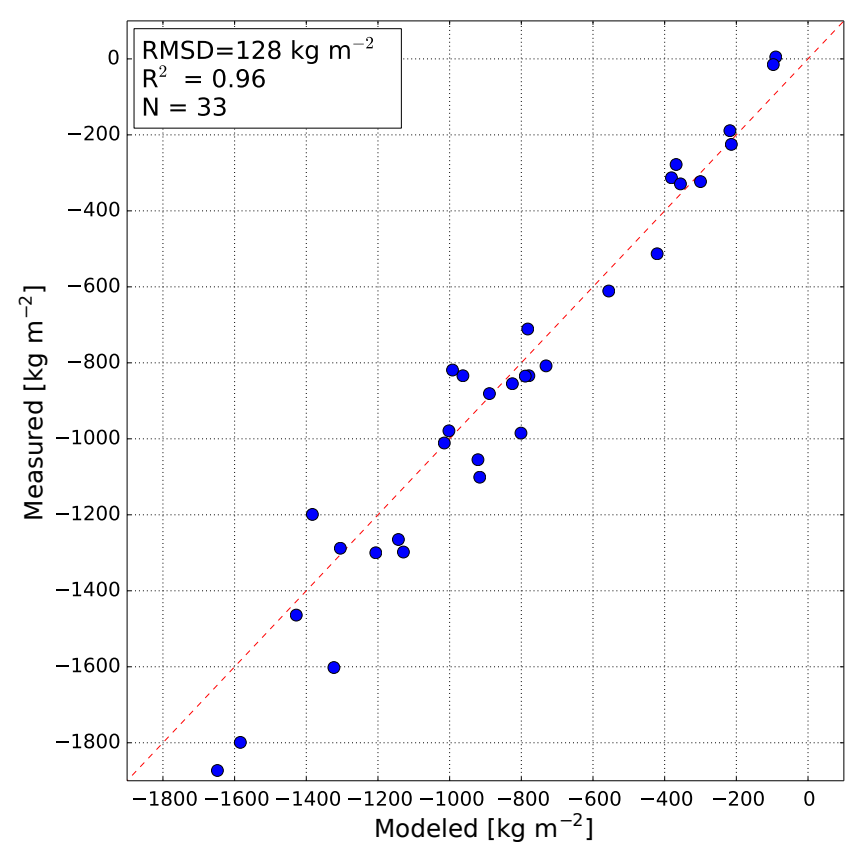

Figure 7. Scatter plot of modeled annual point mass balances against observations.

Thibert et al., 2008; Huss et al., 2009; Carturan et al., 2012) and is lower than reported uncertainties of statistical approaches (e.g., Carturan et al., 2009; Thibert and Vincent, 2009). Since no significant systematic errors such as biases for single stakes or years are detectable, the 47 newly created point values constitute a valuable basis for the reanalysis of the glacier-wide annual balance. Despite the convincing performance, the transferability of the approach is restricted by several factors. First the method is based on data from nearby AWS which are not available for every glacier. Second, the model in its current form cannot be applied to years/locations with persisting snow cover since it is based on observations of the emergence of last year's reference surface. However, snow line observations could for instance be replaced by snow measurements taken at some time in summer. As such observations at Langenferner are missing in 2010 and 2013, the mass balance at only a few stake locations could be modeled in these years. This reduced the number of validation points but did not affect the reanalysis procedure, since measurements for these years are available at most stake locations.

\subsection{Glacier-wide specific annual mass balance}

Mean specific annual mass balances and their altitudinal distribution (Fig. 6) were calculated based on the homogenized set of measured and modeled point values, applying five different extrapolation methods and using the set of newly created annual glacier outlines and topographies. The results for the two contour-line-based extrapolation meth-
Table 2. Statistical evaluation of mass balance series based on different extrapolation methods compared to the reference method: bias, $R^{2}$ and root mean square deviation before (RMSD) and after $\left(\mathrm{RMSD}_{\mathrm{bc}}\right)$ a bias correction of the results.

\begin{tabular}{lrrrrr}
\hline Annual & $B_{\text {orig }}$ & $B_{\text {clt }}$ & $B_{\text {ptr }}$ & $B_{\text {prm }}$ & $B_{\text {ind }}$ \\
\hline Bias & -58 & -2 & -249 & -189 & -247 \\
$R^{2}$ & 0.84 & 1.00 & 0.99 & 0.98 & 0.98 \\
RMSD & 187 & 3 & 256 & 197 & 253 \\
RMSD $_{\text {bc }}$ & 177 & 2 & 56 & 56 & 56 \\
\hline Winter & $B_{\text {orig }}$ & $B_{\text {clt }}$ & $B_{\text {ptr }}$ & $B_{\text {prm }}$ & $B_{\text {ind }}$ \\
\hline Bias & 71 & 2 & -21 & -27 & -26 \\
$R^{2}$ & 0.90 & 1.00 & 0.99 & 0.98 & 0.99 \\
RMSD & 96 & 5 & 29 & 41 & 36 \\
RMSD & 65 & 5 & 19 & 31 & 25 \\
\hline Summer & $B_{\text {orig }}$ & $B_{\text {clt }}$ & $B_{\text {ptr }}$ & $B_{\text {prm }}$ & $B_{\text {ind }}$ \\
\hline Bias & -129 & -4 & -228 & -162 & -221 \\
$R^{2}$ & 0.70 & 1.00 & 0.98 & 0.97 & 0.97 \\
RMSD & 241 & 7 & 235 & 175 & 230 \\
RMSD & 204 & 6 & 57 & 68 & 65 \\
\hline
\end{tabular}

ods are almost identical and differ by only 0 to $5 \mathrm{~kg} \mathrm{~m}^{-2}$ $\left(\mathrm{RMSD}<3 \mathrm{~kg} \mathrm{~m}^{-2}\right.$ ). Consequently, we chose the results obtained by the raster-based contour line method as our reference since this method has the advantage of being less labor intensive than the traditional contour method and it results in high-resolution $(1 \times 1 \mathrm{~m})$ grids of surface mass balance which were also used to calculate annual glacier topographies and outlines (Sect. 3.5).

The results show a persistent mass loss in all observation years. For the reference method, single year numbers vary between $-1556 \pm 47 \mathrm{~kg} \mathrm{~m}^{-2}$ in 2012 and $-246 \pm 31 \mathrm{~kg} \mathrm{~m}^{-2}$ in 2013 , with a study period average of $-1137 \pm 79 \mathrm{~kg} \mathrm{~m}^{-2}$ (Fig. 8 and Table 1). While all applied extrapolation methods display a common signal in terms of interannual mass balance variability $\left(R^{2}>0.98\right)$, the three automatic extrapolations yield mass balances which are considerably more negative than those obtained by the contour line approaches (see Tables 2 and S5 in the Supplement). The respective biases are $-249 \mathrm{~kg} \mathrm{~m}^{-2}$ for the automatic method based on topo to raster, $-189 \mathrm{~kg} \mathrm{~m}^{-2}$ for the profile method and $-247 \mathrm{~kg} \mathrm{~m}^{-2}$ for inverse distance weighting (Fig. 9). Those negative biases can be well explained by the underrepresentation of accumulation areas in the consistent set of point balances (Sect. 3.3.2) on which the three automatic methods are based. This problem is not reflected in the contour-line-based calculations since those benefit from snow line observations, sporadic accumulation measurements and at least a rough knowledge about the amount of accumulation and its spatial distribution. The availability of a few continuous accumulation measurements at fixed locations would strongly reduce the biases of automatic extrapolations and would enable the 


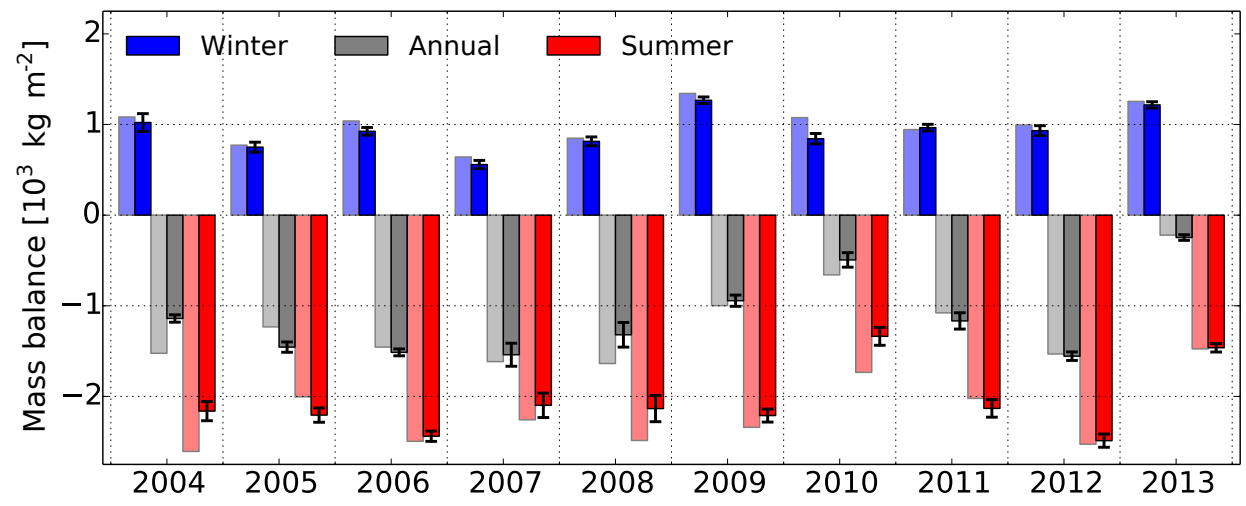

Figure 8. Original and reanalyzed seasonal mass balances at Langenferner during the study period. Error bars account for random uncertainties of the reference method as calculated in this study.

calculation of the glacier-wide mass balance based on a reduced number of point observations and simplified extrapolations. However, this would lead to a loss of information on the spatial pattern of surface mass balance, which constitutes an important component of modern and high-level glacier mass balance monitoring as it is an important source of information for studies on energy balance and other glacier surface processes.

A comparison of the reanalyzed mass balance series to the original record shows that the two records strongly differ in their interannual variability $\left(R^{2}=0.84\right)$, though the bias of the original series $\left(-58 \mathrm{~kg} \mathrm{~m}^{-2}\right)$ is relatively small (Fig. 9, Table 2). Differences for single years are highest for the years 2004 and 2008 when they reach 384 and $319 \mathrm{~kg} \mathrm{~m}^{-2}$, respectively. For 5 of the 10 observation years, differences between the original record and the reanalyzed series exceed the uncertainty range of the reanalyzed reference values. These large differences can mainly be attributed to two causes: (i) the lack of measurements in the upper glacier part during the first half of the study period and the hence insufficient representation of spatial mass balance patterns in the extrapolation of point measurements; (ii) the usage of outdated glacier extents, which in our case biases the calculated glacier-wide annual balances towards more negative values. The latter problem at Langenferner leads to a negative bias of typically about $20 \mathrm{~kg} \mathrm{~m}^{-2}$ after only 1 year. After only a few years without updating the glacier outlines this effect can reach the order of $100 \mathrm{~kg} \mathrm{~m}^{-2}$. This matter is particularly affecting the original mass balance of 2004. For this first observation year, the original analyses were based on glacier outlines of 1996 (Fig. 2) since newer topographic data at this time were not available.

Finally, the diligent consideration of snow line information in the reanalyzed series enabled a more accurate determination of important glaciological key parameters such as ELA and AAR in the individual observation years. All relevant results of the reanalysis, as well as the original numbers for mass balance, ELA and AAR, are listed in Table 1. For

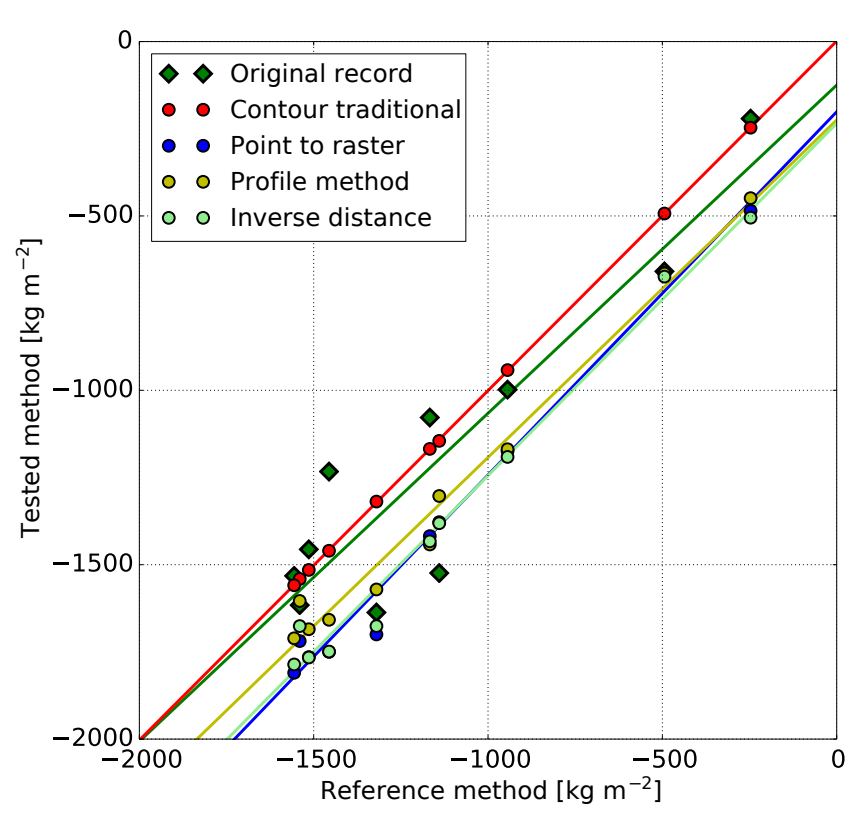

Figure 9. Annual mass balances as obtained from the different extrapolation methods plotted against the results of the reference method. Basic statistics related to this plot are shown in Table 2.

annual and seasonal results of all extrapolation methods the reader is referred to the Supplement.

\subsection{Glacier-wide specific seasonal balance}

In contrast to annual mass balances, no modeling was involved in the calculations of the winter mass balances. However, the same extrapolation methods as used for the calculation of annual balances were applied to derive glacierwide winter balances. Again the two contour-line-based approaches displayed very similar results. For winter mass balances the differences between the two methods are slightly larger than for the annual balances, which can be explained by smaller spatial balance gradients and consequently a 
lower spatial density of contour lines. Nevertheless, the differences for single years do not exceed $12 \mathrm{~kg} \mathrm{~m}^{-2}$. The mean fixed date winter balance for the study period is $929 \pm 52 \mathrm{~kg} \mathrm{~m}^{-2}$ with a maximum of $1267 \pm 34 \mathrm{~kg} \mathrm{~m}^{-2}$ in the wet accumulation period of 2009. The exceptionally dry and warm winter 2007 resulted in the lowest value of $558 \pm 44 \mathrm{~kg} \mathrm{~m}^{-2}$. Note that in this winter period, the lowermost parts of the glacier displayed negative mass balance due to considerable ice melt in late autumn 2006. Except for the year 2011, all reanalyzed winter mass balances are less positive than the original values (bias of original record $=71 \mathrm{~kg} \mathrm{~m}^{-2}$ ). This can be explained by the fact that all applied corrections in our case generally lower the mass balance value and more positive values can only be the result of differences in the spatial extrapolation of point values or the use of different glacier extents, both of which have little impact $\left(<50 \mathrm{~kg} \mathrm{~m}^{-2}\right)$ on the winter balance at Langenferner due to generally small spatial winter balance gradients at this specific glacier.

The correlation between the original and reanalyzed records of winter mass balance is larger $\left(R^{2}=0.90\right)$ than for annual balances, which can be explained by the fact that the same set of point measurements has been used for both series and that differences in glacier-wide values can mainly be attributed to the corrections applied to the original data set (Sect. 3.1). Nevertheless, differences between the original and the reference record exceed the corresponding random uncertainties for 6 out of 10 winter periods. The homogenization of original winter balance point measurements revealed that the recalculation of point winter balances according to the fixed date system generally showed the largest impact of the applied corrections. For the year 2010, the effect of this correction reached $140 \mathrm{~kg} \mathrm{~m}^{-2}$ on the glacier-wide scale ( $17 \%$ of the winter net accumulation). Corrections for snow of the previous hydrological year were showing a smaller effect but are still on the order of up to $100 \mathrm{~kg} \mathrm{~m}^{-2}$ on the glacier-wide scale. For 2011, when the corresponding corrections were already applied in the original series, skipping this correction would change the mean specific winter balance by more than $200 \mathrm{~kg} \mathrm{~m}^{-2}$. The impact of ice ablation during the hydrological winter period was greatest in the years 2004 and 2006 when it reached the order of 30 and $55 \mathrm{~kg} \mathrm{~m}^{-2}$, respectively. On the point scale respective values reach the order of $300 \mathrm{~kg} \mathrm{~m}^{-2}$ in the lower most glacier part, which, in this very dry and warm winter, resulted in a negative fixed date winter balance at the lower part of the glacier tongue. For glaciers with large tongues reaching low elevations or with large sun-exposed area fractions, this issue may be of even higher relevance than at Langenferner.

Values of summer mass balance range from $-2488 \pm 71 \mathrm{~kg} \mathrm{~m}^{-2}$ in 2012 to $-1336 \pm 99 \mathrm{~kg} \mathrm{~m}^{-2}$ in 2010. Differences between original and reanalyzed summer mass balances exceed the uncertainties of the reanalyzed series in 8 out of 10 observation years reaching up to $446 \mathrm{~kg} \mathrm{~m}^{-2}$ in 2004. A comparison of the two series yields
$R^{2}$ of 0.70 while between the individual reanalysis series $R^{2}$ is $\geq 0.97$. Summer balances suffer from the largest uncertainties as they are calculated as a residual from annual and winter mass balances and are hence affected by the uncertainties in both series.

\subsection{Integration of meteorological data in mass balance observations}

The aim of the present study was, amongst others, the creation of a best possible estimate of Langenferner's mass balance during the study period serving as a reference for further investigations on the glacier. But, as already stated in Sect. 3.2, the integration of meteorological data in observational records of glacier mass balance may be problematic because there is a risk of circular reasoning: observational series of glacier mass balance are often used in investigations of glacier response to climate forcing. We argue that this risk is limited since a large part of the systematic influence that meteorological data could have on our time series is canceled out by the calibration of $\Gamma_{i, a}$ and the constraint of matching snow observations. However, this paper and the Supplement provide full insight into the applied reanalysis process and all data partly or fully resulting from the integration of meteorological data are clearly flagged in the tables or in data published through the WGMS or elsewhere. This enables a individual-case user decision on whether these data are suitable for a specific purpose or not.

\subsection{Geodetic mass balance}

The mean surface elevation change at Langenferner during the 8-year period of 2005 to 2013 amounts to $-10.35 \pm 0.21 \mathrm{~m}$. Surface elevation changes in the lowermost glacier part reach the order of $-40 \mathrm{~m}$ while in the highest regions changes on the order of 1 to $3 \mathrm{~m}$ are detectable (Fig. 4). Assuming a bulk glacier density of $850 \pm 60 \mathrm{~kg} \mathrm{~m}^{-3}$, this corresponds to an uncorrected geodetic mass balance of $-9397 \pm 691 \mathrm{~kg} \mathrm{~m}^{-2}$. The correction for differences in snow cover between the two acquisition dates changes the result to $-9596 \pm 694 \mathrm{~kg} \mathrm{~m}^{-2}$. Note that the values slightly differ from those $\left(-9381\right.$ and $-9702 \mathrm{~kg} \mathrm{~m}^{-2}$ ) presented by Galos et al. (2015) since the study in hand makes use of reanalyzed data sets. For the two subperiods 2005 to 2011 and 2011 to 2013 the uncorrected geodetic balances are $-7439 \pm 558$ and $-1908 \pm 228 \mathrm{~kg} \mathrm{~m}^{-2}$, respectively. The corrected values change to $-7436 \pm 560$ and $-2084 \pm 248 \mathrm{~kg} \mathrm{~m}^{-2}$, showing that especially the snow cover correction for the short period 2011 to 2013 leads to a large relative change $(-9 \%)$ in the result. The results of the geodetic analyses are summarized in Table 3 including raw and corrected values, as well as numbers for the individual corrections applied. 
Table 3. Results of the geodetic analyses and the cross-check between glaciological and geodetic method. PoR stands for the observation period, $\Delta Z$ is the mean surface elevation change, $\Delta V$ the volume change, $B_{\text {geod }}$ is the uncorrected geodetic balance assuming a bulk density of $850 \mathrm{~kg} \mathrm{~m}^{-3}$, $\operatorname{corr}_{\mathrm{sc}}$ and corr $_{\mathrm{sd}}$ refer to the corrections for snow cover and survey dates, $B_{\text {geod.corr }}$ refers to the corrected geodetic balance, $\sigma_{\text {geod.total.PoR }}$ is the total random error of $B_{\text {geod.corr }}, B_{\text {glac.PoR }}$ is the cumulated glaciological mass balance, $\sigma_{\text {glac.total.PoR }}$ is the corresponding random uncertainty, $\Delta_{\text {rel }}$ is the relative difference between glaciological and geodetic results and $\delta$ is the reduced discrepancy (Zemp et al., 2013).

\begin{tabular}{rrrrrrrrrrrr}
\hline PoR & $\Delta Z$ & $\Delta V$ & $B_{\text {geod }}$ & corr $_{\text {sc }}$ & corr $_{\text {sd }}$ & $B_{\text {geod.corr }}$ & $\sigma_{\text {geod.total.PoR }}$ & $B_{\text {glac.PoR }}$ & $\sigma_{\text {glac.total.PoR }}$ & $\Delta_{\text {rel }}$ & $\delta$ \\
\hline m & $10^{6} \mathrm{~m}^{3}$ & $\mathrm{~kg} \mathrm{~m}^{-2}$ & $\mathrm{~kg} \mathrm{~m}^{-2}$ & $\mathrm{~kg} \mathrm{~m}^{-2}$ & $\mathrm{~kg} \mathrm{~m}^{-2}$ & $\mathrm{~kg} \mathrm{~m}^{-2}$ & $\mathrm{~kg} \mathrm{~m}^{-2}$ & $\mathrm{~kg} \mathrm{~m}^{-2}$ & $\%$ & - \\
\hline $2005-13$ & -10.35 & -18.98 & -9397 & -198 & -49 & -9644 & 709 & -8964 & 241 & 7.1 & 0.91 \\
$2005-11$ & -8.34 & -15.28 & -7439 & -38 & 41 & -7436 & 560 & -7105 & 234 & 4.5 & 0.55 \\
$2011-13$ & -2.20 & -3.66 & -1908 & -169 & -8 & -2084 & 248 & -1829 & 56 & 12.2 & 1.00 \\
\hline
\end{tabular}

\subsection{Uncertainties in glaciological and geodetic balances}

The largest source of uncertainties in the reanalyzed glaciological record is the spatial extrapolation of point measurements. The largest spread between individual extrapolation methods is shown in the years 2008 and 2009 in which the negative offsets of the automatic extrapolation methods are especially large. We attribute this to very strong spatial mass balance gradients in these 2 years given by the fact that mass balances at stake locations were quite negative, but at the same time snow of the previous winter could sustain throughout the summer in concavely shaped areas of the upper glacier part. While these patterns are reflected in the contour-line-based extrapolations, automatic methods did not capture this due to missing measurements in the respective areas. This shows the importance of the integration of accurate snow line observations in calculations of glacier mass balance (e.g., Østrem and Brugman, 1991; Kaser et al., 2003). For winter balances the largest extrapolation uncertainties occur in 2004 when only 22 point measurements are available. However, this number would most probably be sufficient if the measurements were well distributed over the glacier area (Jansson, 1999), which was not the case in that year. For both annual and winter mass balances, the second largest uncertainty source is given by the uncertainties related to point measurements. For annual balances they are on the order of $22 \mathrm{~kg} \mathrm{~m}^{-2}$ while for winter balances they range from 7 to $16 \mathrm{~kg} \mathrm{~m}^{-2}$ due to the generally higher number of measurements combined with less distinct spatial mass balance gradients. Uncertainty terms for all years and seasons are presented in the Supplement.

Uncertainties in the corrected geodetic balances are mostly determined by the applied density range of $850 \pm 60 \mathrm{~kg} \mathrm{~m}^{-3}$. Other error sources only account for a few percent of the total random error, except for the short period 2011 to 2013, when the remaining uncertainty of the DEM exceeds the uncertainty related to the density assumption.
Table 4. Reduced discrepancies $\delta$ for all extrapolation methods used in this reanalysis and for the original mass balance record. The upper panel shows results without the consideration of basal and internal melt, while the lower panel $(*)$ refers to $\delta$ calculated accounting for subsurface melt. Bold values refer to agreement on the $90 \%$ confidence interval.

\begin{tabular}{lrrrrrr}
\hline PoR & $\delta_{\text {ref }}$ & $\delta_{\text {orig }}$ & $\delta_{\text {clt }}$ & $\delta_{\text {ptr }}$ & $\delta_{\text {prm }}$ & $\delta_{\text {ind }}$ \\
\hline $2005-13$ & $\mathbf{0 . 9 1}$ & $\mathbf{0 . 3 2}$ & $\mathbf{0 . 9 0}$ & $-1.74^{1}$ & $-\mathbf{1 . 1 4}$ & $-1.70^{1}$ \\
$2005-11$ & $\mathbf{0 . 5 5}$ & $-\mathbf{0 . 2 4}$ & $\mathbf{0 . 5 4}$ & $-1.90^{1}$ & $-\mathbf{1 . 3 8}$ & $-1.86^{1}$ \\
$2011-13$ & $\mathbf{1 . 0 0}$ & $\mathbf{1 . 1 9}$ & $\mathbf{0 . 9 8}$ & $-\mathbf{0 . 9 5}$ & $-\mathbf{0 . 4 1}$ & $-\mathbf{0 . 9 3}$ \\
\hline $2005-13^{*}$ & $\mathbf{0 . 5 5}$ & $\mathbf{- 0 . 0 4}$ & $\mathbf{0 . 5 4}$ & $-2.10^{2}$ & $-\mathbf{1 . 4 9}$ & $-2.05^{2}$ \\
$2005-11^{*}$ & $\mathbf{0 . 2 1}$ & $\mathbf{- 0 . 5 8}$ & $\mathbf{0 . 2 0}$ & $-2.24^{2}$ & $-1.72^{1}$ & $-2.20^{2}$ \\
$2011-13^{*}$ & $\mathbf{0 . 7 6}$ & $\mathbf{0 . 9 5}$ & $\mathbf{0 . 7 4}$ & $-\mathbf{1 . 1 9}$ & $-\mathbf{0 . 6 5}$ & $-\mathbf{1 . 1 7}$
\end{tabular}

${ }^{1}$ Agreement on the $95 \%$ confidence interval. ${ }^{2}$ Not acceptable on the $95 \%$ confidence interval.

\subsection{Glaciological versus geodetic method}

Applying Eq. (16) to the results of our glaciological reference method yields $\delta$ values between 0.55 and 1 (Table 3 ) indicating that there is agreement between the glaciological and the geodetic results well within the $90 \%$ confidence interval (Zemp et al., 2013; Sold et al., 2016). Hence, a calibration of the reanalyzed glaciological record is not necessary although we did not yet account for internal or basal melt.

The results of the profile method also fulfill the above criteria for all three (sub) periods and could hence also be regarded as acceptable. The point-to-raster and inverse distance weighting methods fulfill the $90 \%$ confidence criteria only for the period 2011 to 2013 but results are within the $95 \%$ confidence bounds for the other periods (Table 4). However, the three automatic extrapolation methods yield results which are persistently more negative than the geodetic method (Fig. 10), while from a physical perspective the geodetic method, especially during periods of strong glacier mass loss, can generally be expected to display results more negative than the glaciological method due to the effect of internal and basal melt processes. 


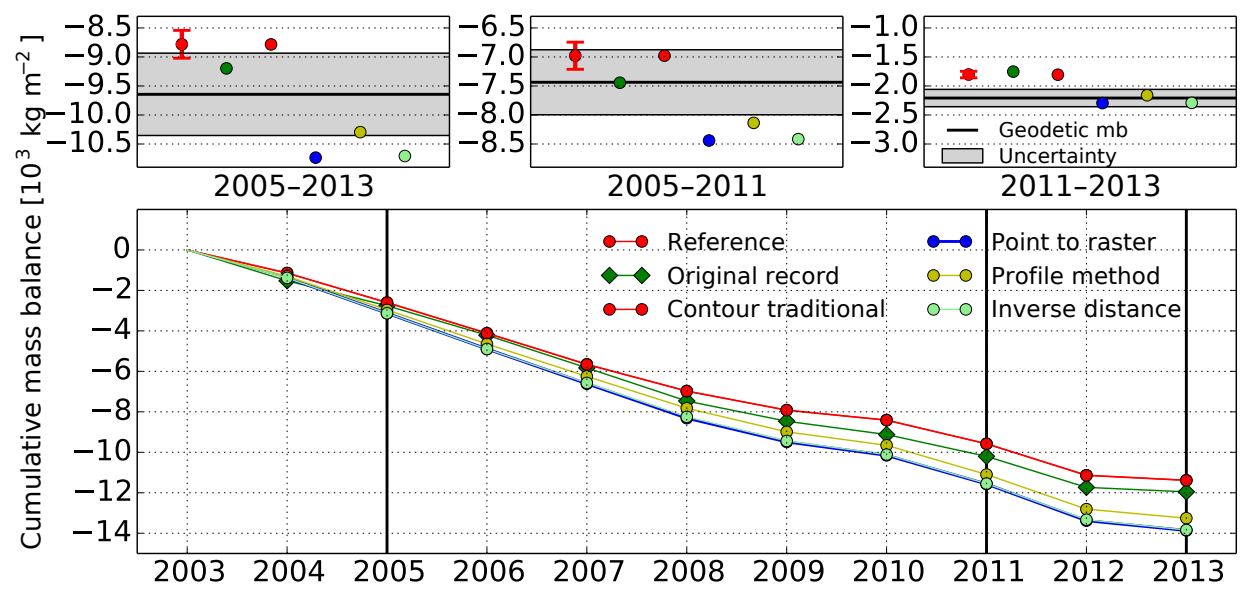

Figure 10. Comparison between geodetic and glaciological mass balances for three periods (upper three subplots) and cumulative series of annual mass balance calculated using the set of extrapolation methods described in the paper.

\subsubsection{The role of basal and internal melt}

Several studies have shown that basal and internal melt can be important contributors to total glacier ablation, depending on the specific glacier and the climatic setting (e.g., Alexander et al., 2011; Oerlemans, 2013; Andreassen et al., 2016). Generally, the most important sources of energy for subsurface melt on temperate glaciers are related to the conversion of potential energy by water runoff inside and at the base of the glacier. The water may originate from precipitation and other accumulation processes or may enter the glacier from outside. In the latter case the water may be warmer than $0{ }^{\circ} \mathrm{C}$ and hence can offer an additional source of thermal energy. Other contributors to basal and internal melt are the geothermal heat flux and the conversion of potential energy related to glacier dynamics (deformation and basal friction).

In order to provide a rough estimate of subsurface melt processes at Langenferner, we calculated the melt contribution of water runoff. We applied a similar approach as used by Andreassen et al. (2016), but, instead of precipitation, we considered water released by melt (Thibert et al., 2008), which was approximated by the reanalyzed summer mass balance. Liquid precipitation instantly running off the glacier and water from outside the glacier were neglected since both play a minor role at Langenferner. For the period 2005 to 2013 our calculation gives a total value of $178 \mathrm{~kg} \mathrm{~m}^{-2}$. Melt caused by geothermal heat and glacier dynamics is estimated based on values in the literature (e.g., Thibert et al., 2008; Alexander et al., 2011; Sold et al., 2016) as 10 and $1 \mathrm{~kg} \mathrm{~m}^{-2} \mathrm{a}^{-1}$, respectively. However, combining the estimates for all the mentioned individual contributors during the 8-year period of 2005 to 2013 results in a total subsurface melt of $266 \mathrm{~kg} \mathrm{~m}^{-2}$, which explains about $37 \%$ of the difference between the glaciological and the geodetic method during the same period.
After recalculating the reduced discrepancy $\delta$ (Eq. 16), taking the estimate for subsurface melt into account, the contour-line-based extrapolation methods show the best agreement with the geodetic results (Table 4). While the results of the profile method are still acceptable on the $90 \%$ confidence interval for the periods 2005 to 2013 and 2011 to 2013 and on the $95 \%$ confidence interval for the period 2005 to 2011, the results of the other two automatic methods (point-to-raster and inverse distance weighting) fulfill neither the $90 \%$ nor the $95 \%$ criteria for 2005 to 2013 and 2005 to 2011, respectively.

\section{Conclusions}

In this paper we have presented a detailed workflow for reanalyzing series of annual and seasonal glacier mass balances. The approach was applied to the 10-year record of Langenferner, a small glacier in the Italian Eastern Alps. Existing sets of annual and seasonal point mass balance data were homogenized based on methodological corrections and were completed by pseudo-observations of point mass balance obtained by a physical model. Based on the homogenized point data, glacier-wide mass balances were reexamined using a variety of extrapolation methods. Finally a detailed uncertainty assessment was performed including a cross-check of glaciological results to those obtained by the geodetic method.

The reanalysis revealed that common problems often neglected in mass balance analyses can significantly disturb the derived interannual mass balance signal. Comparing the reanalyzed results to those of the original record yielded differences in annual mean specific mass balances of up to $384 \mathrm{~kg} \mathrm{~m}^{-2}$. This by far exceeds the uncertainties of the reanalyzed values, which are in the range of 31 to $136 \mathrm{~kg} \mathrm{~m}^{-2}$. Considering that two mass balance series for the same glacier 
and time period are compared, the correlation of the two records is rather low $\left(R^{2}=0.84\right)$. This misfit for annual balances could mainly be attributed to missing point measurements for the upper glacier part in the original data series.

In the reanalysis, this drawback was overcome by applying a process-based mass balance model. After a Monte Carlo-based parameter optimization, the performance of the model was enhanced through individual precipitation tuning for every stake and year using the observed date of ice emergence as a constraint. The validation of modeled annual point balances against independent observations showed a RMSD of $128 \mathrm{~kg} \mathrm{~m}^{-2}$, which is comparable to the uncertainties of glaciological point measurements reported in the literature. The applied model approach can consequently be regarded as a useful tool to generate additional accurate point mass balances given that meteorological data and snow line information such as time lapse photos or satellite images are available.

Uncertainties due to missing updates of rapidly changing glacier geometries represent another important source of uncertainty, especially for annual balances. In our case this problem causes errors on the order of $20 \mathrm{~kg} \mathrm{~m}^{-2}$ after only 1 year growing almost linearly within the study period. To tackle this problem we presented a method which enables the calculation of annual glacier outlines by combining geodetic information on glacier topography and measured surface mass balance.

For winter balances the correlation between original and reanalyzed record is higher $\left(R^{2}=0.90\right)$ than for annual balances, which can be explained by the generally sufficient amount and spatial distribution of winter mass balance measurements. Winter balances at Langenferner are also less sensitive to changes in the spatial distribution of measurements and to missing updates of glacier geometry since in most years there is no significant altitudinal gradient in winter mass balance. Differences between the original and reanalyzed series of winter mass balance mainly originate from the fixed date correction which was applied over the course of the reanalysis. Corrections for snow from the previous hydrological year are also of considerable importance while ice melt at the beginning of the hydrological year only plays a role in 2 years.

We also presented a thorough uncertainty analysis which is transferable to other sites independently of the physical model applied in this study. The analysis revealed that the typical random uncertainty of the reanalyzed mass balances is on the order of $79 \mathrm{~kg} \mathrm{~m}^{-2}$ for annual and about $52 \mathrm{~kg} \mathrm{~m}^{-2}$ for winter mass balances. Numbers for single years/seasons range from 31 to $136 \mathrm{~kg} \mathrm{~m}^{-2}$. The largest part of the uncertainties can be attributed to the extrapolation of point values to the glacier scale, which apparently depend not only on the number and distribution of measurement points but also on annual characteristics such as spatial balance gradients. The propagation of point scale uncertainties to the glacier scale constitutes the second largest error source in our study with typical values of $22 \mathrm{~kg} \mathrm{~m}^{-2}$ for annual and $10 \mathrm{~kg} \mathrm{~m}^{-2}$ for winter balances. Finally, the comparison of the cumulative reanalyzed glaciological mass balance over the period 2005 to 2013 to the geodetic mass balance over the same period yields agreement between the two methods, indicating that there is no significant bias between the two methods and a calibration of the glaciological results is hence not required.

While the calibration (bias correction) of glaciological series based on geodetic measurements has become a common procedure in the reanalysis of glacier mass balance records, the current study also addresses the interannual mass balance variability, as well as related uncertainties. In order to increase the value of mass balance series and to better understand underlying processes, future studies should address this matter by the integration of multi-source data combined with sound uncertainty analyses.

Data availability. All mass balance data resulting from this study were submitted to the world glacier monitoring service. Reanalyzed point values for annual and winter mass balance are listed in the Supplement of this paper. Any further data or information are available on request at the ACINN.

\section{The Supplement related to this article is available online at https://doi.org/10.5194/tc-11-1417-2017-supplement.}

Author contributions. SG designed the study, conducted the gross part of the analyses and wrote the manuscript. CK processed ALS data sets and performed a series of GIS calculations. FM contributed to the study design and performed the bootstrap calculations. LN contributed to the paper design and writing. FC created most of the figures. LR provided the 2011 ALS data and information on ALS uncertainties. WG performed the Monte Carlo model optimization. TM provided the mass balance model and related information. GK helped to refine the manuscript and is the leader of the scientific project under which the study was carried out. All authors helped to improve the manuscript.

Competing interests. The authors declare that they have no conflict of interest.

Acknowledgements. We thank all persons involved in the field work at Langenferner, with special thanks to Rainer Prinz. We are grateful to Roberto Dinale and Michaela Munari from the HOB for the constructive collaboration in coordinating the monitoring activities at Langenferner. Christoph Oberschmied provided his rich archive of photographs, which was a great help in constraining the snow line evolution at the glacier. We thank the two referees Liss M. Andreassen and Emmanuel Thibert whose comments helped to improve the manuscript. The work on this study was financed by Autonome Provinz Bozen - Südtirol, Abteilung Bildungsförderung, Universität und Forschung, and the Austrian Science Fund (FWF) grant V309-N26. 
Edited by: Jon Ove Hagen

Reviewed by: Emmanuel Thibert and Liss M. Andreassen

\section{References}

Abermann, J., Fischer, A., Lambrecht, A., and Geist, T.: On the potential of very high-resolution repeat DEMs in glacial and periglacial environments, The Cryosphere, 4, 53-65, https://doi.org/10.5194/tc-4-53-2010, 2010.

Alexander, D., Shulmeister, J., and Davies, T.: High basal melting rates within high-precipitation temperate glaciers, J. Glaciol., 57, 789-795, https://doi.org/10.3189/002214311798043726, 2011.

Andreassen, L. M., Kjøllmoen, B., Rasmussen, A., Melvold, K., and Nordli, Ø.: Langfjordjøkelen, a rapidly shrinking glacier in northern Norway, J. Glaciol., 58, 581-593, https://doi.org/10.3189/2012JoG11J014, 2012.

Andreassen, L. M., Elvehøy, H., Kjøllmoen, B., and Engeset, R. V.: Reanalysis of long-term series of glaciological and geodetic mass balance for 10 Norwegian glaciers, The Cryosphere, 10, 535-552, https://doi.org/10.5194/tc-10-535-2016, 2016.

Barandun, M., Huss, M., Sold, L., Farinotti, D., Azisov, E., Salzmann, N., Usubaliev, R., Merkushkin, A., and Hoelzle, M.: Re-analysis of seasonal mass balance at Abramov glacier 1968-2014, J. Glaciol., 61, 1103-1117, https://doi.org/10.3189/2015JoG14J239, 2015

Carturan, L., Cazorzi, F., and Dalla Fontana, G.: Enhanced estimation of glacier mass balance in unsampled areas by means of topographic data, Ann. Glaciol., 50, 37-46, https://doi.org/10.3189/172756409787769519, 2009.

Carturan, L., Cazorzi, F., and Dalla Fontana, G.: Distributed massbalance modelling on two neighbouring glaciers in OrtlesCevedale, Italy, from 2004 to 2009, J. Glaciol., 58, 467-486, https://doi.org/10.3189/2012JoG11J111, 2012.

Carturan, L., Filippi, R., Seppi, R., Gabrielli, P., Notarnicola, C., Bertoldi, L., Paul, F., Rastner, P., Cazorzi, F., Dinale, R., and Dalla Fontana, G.: Area and volume loss of the glaciers in the Ortles-Cevedale group (Eastern Italian Alps): controls and imbalance of the remaining glaciers, The Cryosphere, 7, 13391359, https://doi.org/10.5194/tc-7-1339-2013, 2013.

Carturan, L., Cazorzi, F., De Blasi, F., and Dalla Fontana, G.: Air temperature variability over three glaciers in the Ortles-Cevedale (Italian Alps): effects of glacier fragmentation, comparison of calculation methods, and impacts on mass balance modeling, The Cryosphere, 9, 1129-1146, https://doi.org/10.5194/tc-9-11292015, 2015.

Church, J., Clark, P., Cazenave, A., Gregory, J., Jevrejeva, S., Levermann, A., Merrifield, M., Milne, G., Nerem, R., Nunn, P., Payne, A., Pfeffer, W., Stammer, D., and Unnikrishnan, A.: Sea Level Change, book section 13, 1137-1216, Cambridge University Press, Cambridge, United Kingdom and New York, NY, USA, https://doi.org/10.1017/CBO9781107415324.026, 2013.

Cogley, J. G.: Geodetic and direct mass balance measurements: Comparison and joint analysis, Ann. Glaciol., 50, 96-100, https://doi.org/10.3189/172756409787769744, 2009.

Cogley, J. G., Hock, R., Rasmussen, L. A., Arendt, A. A., Bauder, A., Braithwaite, R. J., Jansson, P., Kaser, G., Möller, M., Nicholson, L., and Zemp, M.: Glossary of Glacier Mass Balance and
Related Terms, IHP-VII Technical Documents in Hydrology No. 86, IACS Contribution No. 2, UNESCO-IHP, Paris, 2011.

Cox, L. H. and March, R. S.: Comparison of geodetic and glaciological mass balance, Gulkana Glacier, Alaska, USA, J. Glaciol., 50 , 363-370, https://doi.org/10.3189/172756504781829855, 2004.

Cuffey, K. M. and Paterson, W. S. B.: The Physics of Glaciers, Elsevier, Amsterdam, 4 edn., 2010.

D’Agata, C., Bocchiola, D., Maragno, D., Smiraglia, C., and Diolaiuti, G. A.: Glacier shrinkage driven by climate change during half a century (1954-2007) in the Ortles-Cevedale group (Stelvio National Park, Lombardy, Italian Alps), Theor. Appl. Climatol., 116, 169-190, https://doi.org/10.1007/s00704-013-0938-5, 2014.

Dyurgerov, M. B. and Meier, M. F.: Twentieth century climate change: Evidence from small glaciers, P. Natl. Acad. Sci. USA 97, 1406-1411, https://doi.org/10.1073/pnas.97.4.1406, 2000.

Eckert, N., Baya, H., Thibert, E., and Vincent, C.: Extracting the temporal signal from a winter and summer mass-balance series: Application to a six-decade record at Glacier de Sarennes, French Alps, J. Glaciol., 57, 134-150, https://doi.org/10.3189/002214311795306673, 2011.

Efron, B.: Bootstrap Methods: Another Look at the Jacknife, Ann. Stat., 7, 1-26, 1979.

Escher-Vetter, H., Kuhn, M., and Weber, M.: Four decades of winter mass balance of Vernagtferner and Hintereisferner, Austria: Methodology and results, Ann. Glaciol., 50, 87-95, https://doi.org/10.3189/172756409787769672, 2009.

Fountain, A. G. and Vecchia, A.: How many Stakes are Required to Measure the Mass Balance of a Glacier?, Geogr. Ann. A, 81, 563-573, https://doi.org/10.1111/1468-0459.00084, 1999.

Funk, M., Morell, R., and Stahel, W.: Mass Balance of Griesgletscher 1961-1994: Different Methods of Determination, Zeitschrift für Gletscherkunde und Glazialgeologie, 33, 41-56, 1997.

Galos, S., Klug, C., Prinz, R., Rieg, L., Sailer, R., Dinale, R., and Kaser, G.: Recent glacier changes and related contribution potential to river discharge in the Vinschgau/Val Venosta, Italian Alps, Geogr. Fis. Din. Quat., 38, 143-154, https://doi.org/10.4461/GFDQ.2015.38.13, 2015.

Gardner, A. S., Moholdt, G., Cogley, J. G., Wouters, B., Arendt, A. A., Wahr, J., Berthier, E., Hock, R., Pfeffer, W. T., Kaser, G., Ligtenberg, S. R. M., Bolch, T., Sharp, M. J., Hagen, J. O., van den Broeke, M. R., and Paul, F.: A reconciled estimate of glacier contributions to sea level rise: 2003 to 2009., Science, 340, 852-857, https://doi.org/10.1126/science.1234532, 2013.

Gurgiser, W., Mölg, T., Nicholson, L., and Kaser, G.: Mass-balance model parameter transferability on a tropical glacier, J. Glaciol. 59, 845-858, https://doi.org/10.3189/2013JoG12J226, 2013.

Haberkorn, A., Phillips, M., Kenner, R., Rhyner, H., Bavay, M., Galos, S. P., and Hoelzle, M.: Thermal Regime of Rock and its Relation to Snow Cover in Steep Alpine Rock Walls: Gemsstock, Central Swiss Alps, Geogr. Ann. A, 97, 579-597, https://doi.org/10.1111/geoa.12101, 2015.

Haefeli, R.: The ablation gradient and the retreat of a glacier tongue, in: Syposium of Obergurgl, IASH Publication, 58, 49-59, 1962.

Hock, R. and Jensen, H.: Application of Kriging Interpolation for Glacier Mass Balance Computations, Geogr. Ann. A, 81, 611619, https://doi.org/10.1111/1468-0459.00089, 1999. 
Hoinkes, H., Howorka, F., and Schneider, W.: Glacier mass budget and mesoscale weather in the Austrian Alps 1964 to 1966, Proceedings of the International Commission of Snow and Ice, 79, 241-254, 1967.

Huss, M.: Density assumptions for converting geodetic glacier volume change to mass change, The Cryosphere, 7, 877-887, https://doi.org/10.5194/tc-7-877-2013, 2013.

Huss, M. and Bauder, A.: 20th-century climate change inferred from four long-term point observations of seasonal mass balance, Ann. Glaciol., 50, 207-214, https://doi.org/10.3189/172756409787769645, 2009.

Huss, M., Bauder, A., and Funk, M.: Homogenization of longterm mass balance time series, Ann. Glaciol., 50, 198-206, https://doi.org/10.3189/172756409787769627, 2009.

Huss, M., Hock, R., Bauder, A., and Funk, M.: Conventional versus reference-surface mass balance, J. Glaciol., 58, 278-286, https://doi.org/10.3189/2012JoG11J216, 2012.

Huss, M., Sold, L., Hoelzle, M., Stokvis, M., Salzmann, N., Farinotti, D., and Zemp, M.: Towards remote monitoring of sub-seasonal glacier mass balance, Ann. Glaciol., 54, 75-83, https://doi.org/10.3189/2013AoG63A427, 2013.

Hutchinson, M. F.: Adding the Z-Dimension, in: Handbook of Geographic Information Science, Blackwell, 2008.

Hutchinson, M. F., Xu, T., and Stein, J. A.: Recent Progress in the ANUDEM Elevation Gridding Procedure, in: Geomorphometry 2011, Redlands, California, USA, 2011.

Jansson, P.: Effect of uncertainties in measured variables on the calculated mass balance of Storglaciären, Geogr. Ann. A, 81, 633642, https://doi.org/10.1111/1468-0459.00091, 1999.

Joerg, P. C., Morsdorf, F., and Zemp, M.: Uncertainty assessment of multi-temporal airborne laser scanning data: A case study on an Alpine glacier, Remote Sens. Environ., 127, 118-129, https://doi.org/10.1016/j.rse.2012.08.012, 2012.

Kaser, G., Munari, M., Noggler, B., Oberschmied, C., and Valentini, P.: Ricerche sul bilancio di massa del Ghiacciaio di Fontana Bianca (Weissbrunnferner) nel Gruppo Ortles-Cevedale, Geogr. Fis. Din. Quat., 18, 277-280, 1995.

Kaser, G., Fountain, A., and Jansson, P.: A manual for monitoring the mass balance of mountain glaciers, IHP-VI Technical documents in Hydrology, 59, 135 pp., 2003.

Kaser, G., Cogley, J. G., Dyurgerov, M. B., Meier, M. F., and Ohmura, A.: Mass balance of glaciers and ice caps: Consensus estimates for 1961-2004, Geophys. Res. Lett., 33, 1-5, https://doi.org/10.1029/2006GL027511, 2006.

Koblet, T., Gärtner-Roer, I., Zemp, M., Jansson, P., Thee, P., Haeberli, W., and Holmlund, P.: Reanalysis of multi-temporal aerial images of Storglaciären, Sweden (1959-99) - Part 1: Determination of length, area, and volume changes, The Cryosphere, 4 , 333-343, https://doi.org/10.5194/tc-4-333-2010, 2010.

Kronenberg, M., Barandun, M., Hoelzle, M., Huss, M., Farinotti, D., Azisov, E., Usubaliev, R., Gafurov, A., Petrakov, D., and Kääb, A.: Mass-balance reconstruction for Glacier No. 354, Tien Shan, from 2003 to 2014, Ann. Glaciol., 57, 92-102, https://doi.org/10.3189/2016AoG71A032, 2016.

Kuhn, M., Abermann, J., Bacher, M., and Olefs, M.: The transfer of mass-balance profiles to unmeasured glaciers, Ann. Glaciol., 50, 185-190, https://doi.org/10.3189/172756409787769618, 2009.

Lliboutry, L.: Multivariate statistical analysis of glacier annual balances, J. Glaciol., 13, 371-392, 1974.
MacDougall, A. H. and Flowers, G. E.: Spatial and temporal transferability of a distributed energy-balance glacier melt model, J. Climate, 24, 1480-1498, https://doi.org/10.1175/2010JCLI3821.1, 2011.

Machguth, H., Purves, R. S., Oerlemans, J., Hoelzle, M., and Paul, F.: Exploring uncertainty in glacier mass balance modelling with Monte Carlo simulation, The Cryosphere, 2, 191204, https://doi.org/10.5194/tc-2-191-2008, 2008.

Mölg, T., Cullen, N. J., Hardy, D. R., Winkler, M., and Kaser, G.: Quantifying climate change in the tropical midtroposphere over East Africa from glacier shrinkage on Kilimanjaro, J. Climate, 22, 4162-4181, https://doi.org/10.1175/2009JCLI2954.1, 2009a.

Mölg, T., Cullen, N. J., and Kaser, G.: Solar radiation, cloudiness and longwave radiation over low-latitude glaciers: Implications for mass-balance modelling, J. Glaciol., 55, 292-302, https://doi.org/10.3189/002214309788608822, 2009b.

Mölg, T., Maussion, F., Yang, W., and Scherer, D.: The footprint of Asian monsoon dynamics in the mass and energy balance of a Tibetan glacier, The Cryosphere, 6, 1445-1461, https://doi.org/10.5194/tc-6-1445-2012, 2012.

Oerlemans, J.: A note on the water budget of temperate glaciers, The Cryosphere, 7, 1557-1564, https://doi.org/10.5194/tc-7-15572013, 2013.

Østrem, G. and Brugman, M.: Glacier Mass-Balance Measurements: A Manual for Field and Office Work, NHRI Science Report, Saskatoon, Canada, https://doi.org/10.2307/1551489, 1991.

Østrem, G. and Haakensen, N.: Map Comparison or Traditional Mass-balance Measurements: Which Method is Better?, Geogr. Ann. A, 81, 703-711, https://doi.org/10.1111/1468-0459.00098, 1999.

Paul, F.: The influence of changes in glacier extent and surface elevation on modeled mass balance, The Cryosphere, 4, 569-581, https://doi.org/10.5194/tc-4-569-2010, 2010.

Pelto, M. S.: The impact of sampling density on glacier mass balance determination, Hydrol. Process., 14, 3215-3225, https://doi.org/10.1002/10991085(20001230)14:18<3215::AID-HYP197>3.0.CO;2-E, 2000.

Rasmussen, L. A.: Altitude variation of glacier mass balance in Scandinavia, Geophys. Res. Lett., 31, L13401, https://doi.org/10.1029/2004GL020273, 2004.

Rolstad, C., Haug, T., and Denby, B.: Spatially integrated geodetic glacier mass balance and its uncertainty based on geostatistical analysis: Application to the western Svartisen ice cap, Norway, J. Glaciol., 55, 666-680, https://doi.org/10.3189/002214309789470950, 2009.

Sauter, T. and Galos, S. P.: Effects of local advection on the spatial sensible heat flux variation on a mountain glacier, The Cryosphere, 10, 2887-2905, https://doi.org/10.5194/tc-10-28872016, 2016.

Shaw, T. E., Brock, B. W., Fyffe, C. L., Pelliciotti, F., Rutter, N., and Diotri, F.: Air temperature distribution and energy-balance modelling of a debris-covered glacier, J. Glaciol., 62, 185-198, https://doi.org/10.1017/jog.2016.31, 2016.

Sold, L., Huss, M., Machguth, H., Joerg, P. C., Leysinger Vieli, G., Linsbauer, A., Salzmann, N., Zemp, M., and Hoelzle, M.: Mass Balance Re-analysis of Findelengletscher, Switzerland; Benefits of Extensive Snow Accumulation Measurements, Front. Earth Sci., 4, 18, https://doi.org/10.3389/feart.2016.00018, 2016. 
Thibert, E. and Vincent, C.: Best possible estimation of mass balance combining glaciological and geodetic methods, Ann. Glaciol., 50, 112-118, https://doi.org/10.3189/172756409787769546, 2009.

Thibert, E., Vincent, C., Blanc, R., and Eckert, N.: Glaciological and Volumetric Mass Balance Measurements: An error analysis over 51 years, Sarennes Glacier, French Alps, J. Glaciol., 54, 522532, 2008

WGMS: Global Glacier Change Bulletin No.1 (20122013), ICSU(WDS)/IUGG(IACS)/UNEP/UNESCO/WMO, World Glacier Monitoring Service, Zürich, Switzerland, https://doi.org/10.5904/wgms-fog-2015-11, 2015.

Zemp, M., Hoelzle, M., and Haeberli, W.: Six decades of glacier mass-balance observations: A review of the worldwide monitoring network, Ann. Glaciol., 50, 101-111, https://doi.org/10.3189/172756409787769591, 2009.

Zemp, M., Jansson, P., Holmlund, P., Gärtner-Roer, I., Koblet, T., Thee, P., and Haeberli, W.: Reanalysis of multi-temporal aerial images of Storglaciären, Sweden (1959-99) - Part 2: Comparison of glaciological and volumetric mass balances, The Cryosphere, 4, 345-357, https://doi.org/10.5194/tc-4-345-2010, 2010.
Zemp, M., Thibert, E., Huss, M., Stumm, D., Rolstad Denby, C., Nuth, C., Nussbaumer, S. U., Moholdt, G., Mercer, A., Mayer, C., Joerg, P. C., Jansson, P., Hynek, B., Fischer, A., Escher-Vetter, H., Elvehøy, H., and Andreassen, L. M.: Reanalysing glacier mass balance measurement series, The Cryosphere, 7, 12271245, https://doi.org/10.5194/tc-7-1227-2013, 2013.

Zemp, M., Frey, H., Gärtner-Roer, I., Nussbaumer, S. U., Hoelzle, M., Paul, F., Haeberli, W., Denzinger, F., Ahlstrøm, A. P., Anderson, B., Bajracharya, S., Baroni, C., Braun, L. N., Càceres, B. E., Casassa, G., Cobos, G., Dàvila, L. R., Delgado Granados, H., Demuth, M. N., Espizua, L., Fischer, A., Fujita, K., Gadek, B., Ghazanfar, A., Hagen, J. O., Holmlund, P., Karimi, N., Li, Z., Pelto, M., Pitte, P., Popovnin, V. V., Portocarrero, C. A., Prinz, R., Sangewar, C. V., Severskiy, I., Sigurdsson, O., Soruco, A., Usubaliev, R., and Vincent, C.: Historically unprecedented global glacier decline in the early 21 st century, J. Glaciol., 61, 745-762, https://doi.org/10.3189/2015JoG15J017, 2015. 